Article

\title{
Fault Diagnosis and Tolerant Control of Three-Level Neutral-Point Clamped Inverters in Motor Drives
}

\author{
Kuei-Hsiang Chao * ${ }^{-10}$ and Chen-Hou Ke \\ Department of Electrical Engineering, National Chin-Yi University of Technology, Taichung 41170, Taiwan; \\ e00402125@gmail.com \\ * Correspondence: chaokh@ncut.edu.tw; Tel.: +886-4-2392-4505 (ext. 7272); Fax: +886-4-2392-2156
}

Received: 3 October 2020; Accepted: 26 November 2020; Published: 29 November 2020

\begin{abstract}
This paper presents an extension theory-based assessment method to perform fault diagnosis for inverters in motor driving systems. First, a three-level neutral-point clamped (NPC) inverter is created using the PSIM software package to simulate faults for any power transistor in the NPC-type inverter. Fast Fourier transformation is used to transform the line current signals in the time domain into a spectrum in the frequency domain for analysis of the corresponding spectrum of features of the inverter for faults with different power transistors. Then, the relationships between fault types and specific spectra are established as characteristics for the extension assessment method, which is then used to create a smart fault diagnosis system for inverters. Fault-tolerant control (FTC) is used here when the rated output of a faulty inverter is decreased in order to maintain balanced output in three phases by changing the framework of the transistor connection. This is performed to reinforce the reliability of the inverter. Finally, by the simulation and experimental results, the feasibility of the proposed smart fault diagnosis system is confirmed. The proposed fault diagnosis method is advantageous due to its minimal use of data and lack of a learning process, which thereby reduces the fault diagnosis time and makes the method easily used in practice. The proposed fault-tolerant control strategy allows both online and smooth switching in the wiring structure of the inverter.
\end{abstract}

Keywords: extension theory; smart fault diagnosis; three-level neutral-point clamped inverters; line current spectrum feature; fault-tolerant control

\section{Introduction}

Compared to two-level inverters, multi-level inverters [1-5] exert less voltage stress on switches, feature smaller change rates in their output voltages $(d v / d t)$, and can be applied in high power scenarios. As multi-level inverters incorporate multiple power transistors that are connected in both series and parallel, thus making the output line-to-ground voltage waves embedded with many step-like waveforms, their waveforms become step-like voltage waveforms which are better approximated in the form of sine waves, thus being suitable for reducing harmonic components.

Multi-level inverters are generally divided as diode-clamped, neutral-point clamped (NPC, I-type), cascaded $\mathrm{H}$-bridge (CHB), and flying capacitor inverters. Of these types, three-level diode-clamped inverters [6] are widely used due to their simple circuit and ease of control. The inverter works by dividing, using capacitors, the voltage on DC side equally into three voltage levels $(+V d c / 2,0$, and $-V d c / 2$ ), allowing the output voltage to change in three modes, thus, with diodes and switches, clamping the output voltage at a neutral point on the DC side. Yet, as the switches may be damaged when operating in high-current or high-temperature conditions over extended periods of time, components aging, faulty drive circuits, and other faults, thereby resulting in an inability to work normally, multi-level inverters should be designed with a fault detection mechanism and fault-tolerant control in the hope of operation without disruption in the event of a faulty inverter component [7-9]. 
In the past, faults in motor drive systems have been diagnosed based on messages from measurement instruments that are shown directly by numbers or waveforms, which allows easy and fast indication for fault occurrence. Such a practice requires on-site operators to determine (directly and from their own experience) what fault a message indicates for subsequent repairs and component replacement as needed. Such a conventional method of fault diagnosis $[10,11]$ tends to lead to misjudgment for fault points, causing unnecessary wastes of effort and time for repairs and component replacement. Hence, a new technology for diagnosing system faults deserves study. In this regard, there has been much effort made in both Taiwan and overseas [12-15]. The methods that have resulted from these efforts combine more than two algorithms to form an artificial intelligence (AI) system for motor fault diagnosis, which can increase the efficiency in fault diagnosis for motor drive systems and thus helps save labor and time costs. These AI systems are only suitable for motor fault diagnosis and cannot be directly applied to fault diagnosis for multi-level inverters. As such, in the research of the same diagnosis, some researchers have used artificial neural networks (ANNs) to create fault diagnosis systems [16-19]. ANN methods perform diagnosis faster, yet they require massive data quantities for learning. Therefore, the accuracy of the fault diagnosis is based on the amount of learning data and the correctness of the learning process. In [20], an effective control strategy including fault detection, localization, and tolerant operation was proposed for a modular multi-level converter with a transistor open-circuit fault; however, this method is only applicable to a large number of series-connected two-level converter modules, and only for AC-to-DC converters. A novel fault-tolerant control strategy was proposed in [21] for bypassing converter submodules (SM) with faults and re-regulating the SM capacitor voltage and carrier phase-shift angle to maintain the main components of circulating current, additionally reducing the total harmonic distortion (THD) of the grid-connected current to enable the stable operation of the photovoltaic inverter; however, this method is also only suitable for a large number of series-connected two-level inverters. A detailed analysis of a single open-switch fault for a NPC active rectifier was presented in [22]. The study proposed a fault-tolerant control method to reduce the effect of the open-switch fault via compensation with a distorted reference voltage. Although this method could be used with a three-level NPC converter, it can only be used in AC-to-DC converters, but not in inverters. A fast fault diagnosis scheme in a grid-connected photovoltaic (PV) system based on applying the combination of wavelet multi-resolution singular spectrum entropy and a support vector machine was proposed in [23] to identify different types of grid faults in a three-phase grid-tied PV system; however, the calculation procedure of this fault diagnosis method is quite complex and it is aimed at fault detection for a PV system, rather than the diagnosis of the inverter. A fault prognostics method which makes full use of the similarities between inverter clusters was proposed in [24]. Although the divergence of inverter clusters could be used to predict inverter faults, the process for this fault diagnosis method is quite complicated and the calculation procedure is also very complicated. A diagnostic method for an open-circuit transistor failure in a hybrid active neutral-point clamped (HANPC) inverter was proposed in [25]. By analyzing the individual characteristics of each transistor failure, it is possible to detect the exact location of the failed transistors in a short period; however, this method can only diagnose transistor faults in the same leg, and other legs will have the same characteristics, so it is impossible to determine exactly which leg contains the faulty transistor.

In contrast, extension theory-based methods do not require large data quantities for training as they feature models of matter-elements, the coupling of qualification and quantification, and non-closure [26-30], while the distances and rank values makes it possible to establish correlation functions for fault types, and the correlation degrees can be used to identify fault types, thus reducing the learning process and making determination easier, faster, and more accurate. Hence, this study proposes an intelligent fault-tolerant control system based on extension theory for locating faults in a three-level NPC-type inverter. First, the frequency spectra of output line current waveforms are extracted during a power transistor failure event and used as feature values for fault detection. Therefore, the proposed extension theory-based method can be applied to accurately locate a faulty 
power transistor. Subsequently, a fault-tolerant control strategy is used to maintain the three-phase balanced line voltage output if any power semiconductor switch of the inverter fails. Figure 1 illustrates the overall architecture of the extension theory-based fault-diagnosis and fault-tolerant control system proposed herein for NPC-type inverters.

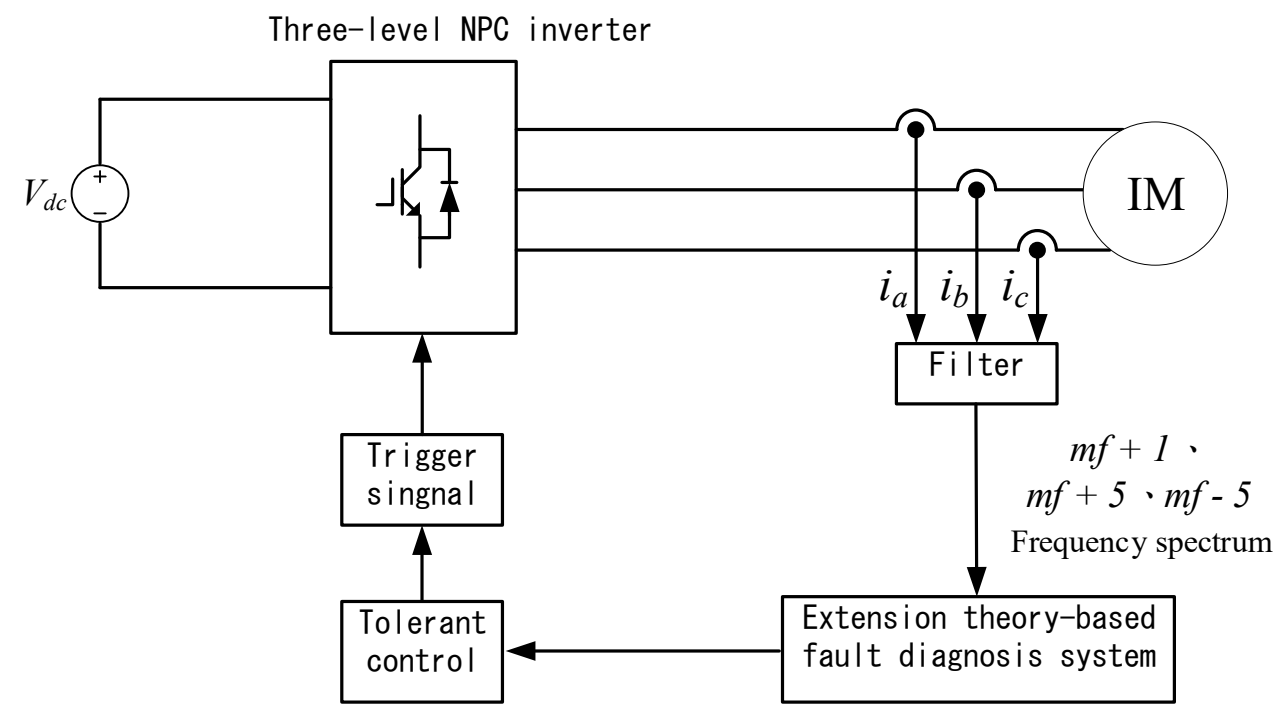

Figure 1. Framework for the extension theory-based fault diagnosis and tolerant control system for neutral-point clamped-type (NPC-type) inverters.

This paper is organized as follows: First, the characteristics of switch faults for three-level NPC-type inverters are discussed in Section 2. Then, in Section 3, the concept of extension theory is described in detail. The procedure for using the extension theory-based fault diagnosis method for a three-level NPC-type inverter is explained in Section 4. Practical tests are detailed in Section 5 to demonstrate the effectiveness of the proposed fault diagnosis method. Finally, in Section 6, fault-tolerant control in the event of power switch failure in the three-level NPC-type inverter is analyzed, and the simulation and experimental results are used to prove the feasibility of the method.

\section{Characteristics of Faults for Three-Level Inverters}

Considering research on inverter fault diagnosis, this paper targets a three-level NPC inverter as shown in Figure 2. In general, faults for inverters come in three types: short-circuit faults, open-circuit faults, and trigger signal faults. A short-circuit fault arises when a switch component is blown due to an overly high voltage across both ends of the switch. An open-circuit fault refers to a power transistor without a trigger signal to actuate conductivity through it. A trigger signal fault is the receipt, by a switch component, of an incorrect trigger signal for command. 


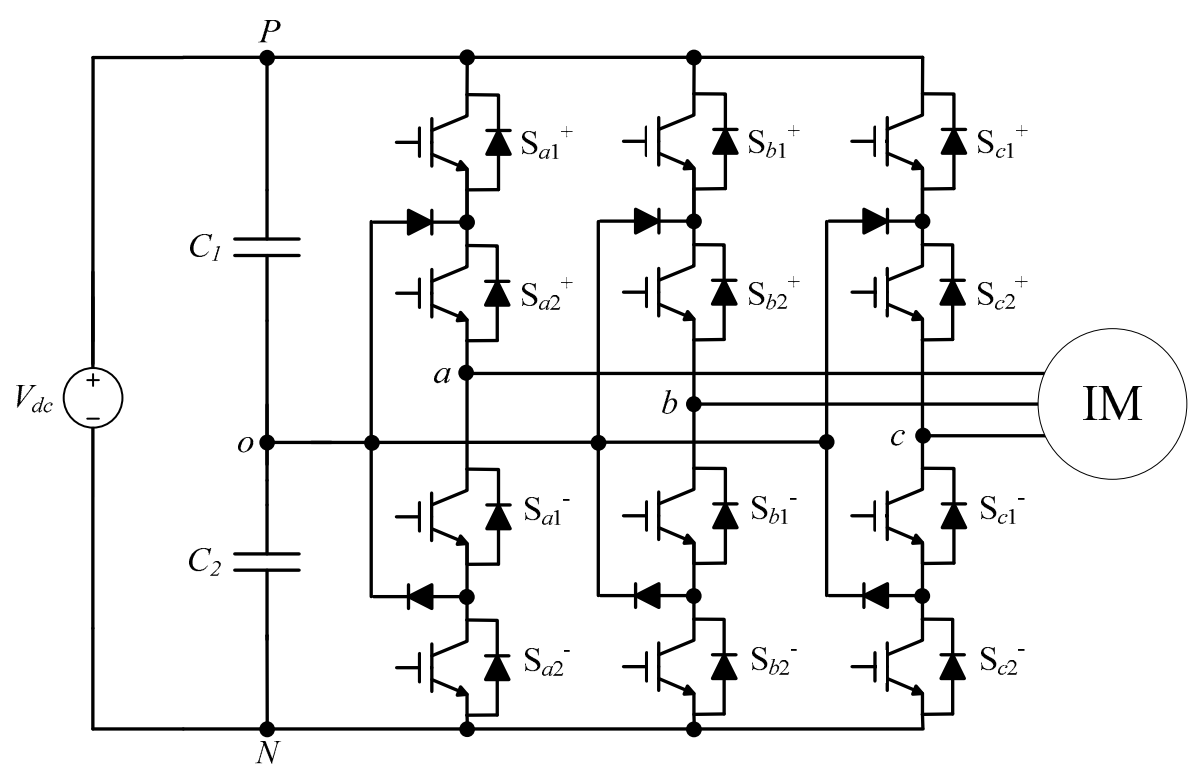

Figure 2. Framework for three-level NPC inverters.

The PSIM software package is the ultimate simulation environment for power electronics and motor control and was developed by PowerSIM. Using the PSIM software package, a simulation environment for three-level NPC inverters was created and used to investigate the diagnosis of faults occurring on any switch at any time. It was observed from the simulations and analysis that the output waveform measured on an inverter in normal working conditions was a balanced three-phase waveform. For example, when the inverter has a working frequency at $60 \mathrm{~Hz}$ without a faulty power transistor, the output waveforms of its line currents and their frequency spectra are given as shown in Figures 3 and 4, respectively. Figure 3 reveals that the waveforms for the line currents are of the same magnitude and all are sine waves, where each is different in phase by $120^{\circ}$, which is typical of the balanced three-phase characteristic. Regarding the parameter setting of the motor drive, a $300 \mathrm{~V}$ DC inverter with a switching frequency of $18 \mathrm{kHz}$ was connected to an induction motor. The frequency spectra for line currents $i_{a}, i_{b}$, and $i_{c}$ for an inverter working at $60 \mathrm{~Hz}$ without a faulty switch are shown in Figure 4. We can see from Figure 4 that the frequency spectra at $m_{f}-5, m_{f}+1$, and $m_{f}+5$, multiplied by the working frequency, are very small. Hence, the values of the frequency spectra at such frequencies were used in this paper as the feature spectra for faults, where $m_{f}$ is defined as the frequency modulation index:

$$
m_{f} \triangleq \frac{f_{\text {carrier }}}{f_{\text {reference }}}=\frac{f_{\text {tri }}}{f_{\text {sin }}}
$$

where $f_{t r i}$ is the frequency of a triangular carrier wave, i.e., the switching frequency of inverter $(18 \mathrm{kHz}$ here) and $f_{\sin }$ is a sine wave frequency $(60 \mathrm{~Hz}$ here) and also the working frequency of the inverter. Therefore, its frequency modulation index $m_{f}$ is 300 . Based on this, the frequency spectra for line currents $i_{a}, i_{b}$, and $i_{c}$ for an inverter working at $60 \mathrm{~Hz}$ without a faulty switch at $m_{f}-5, m_{f}+1$, and $m_{f}+5$, multiplied by the working frequency, are $17.7,18.06$, and $18.3 \mathrm{kHz}$, respectively. 


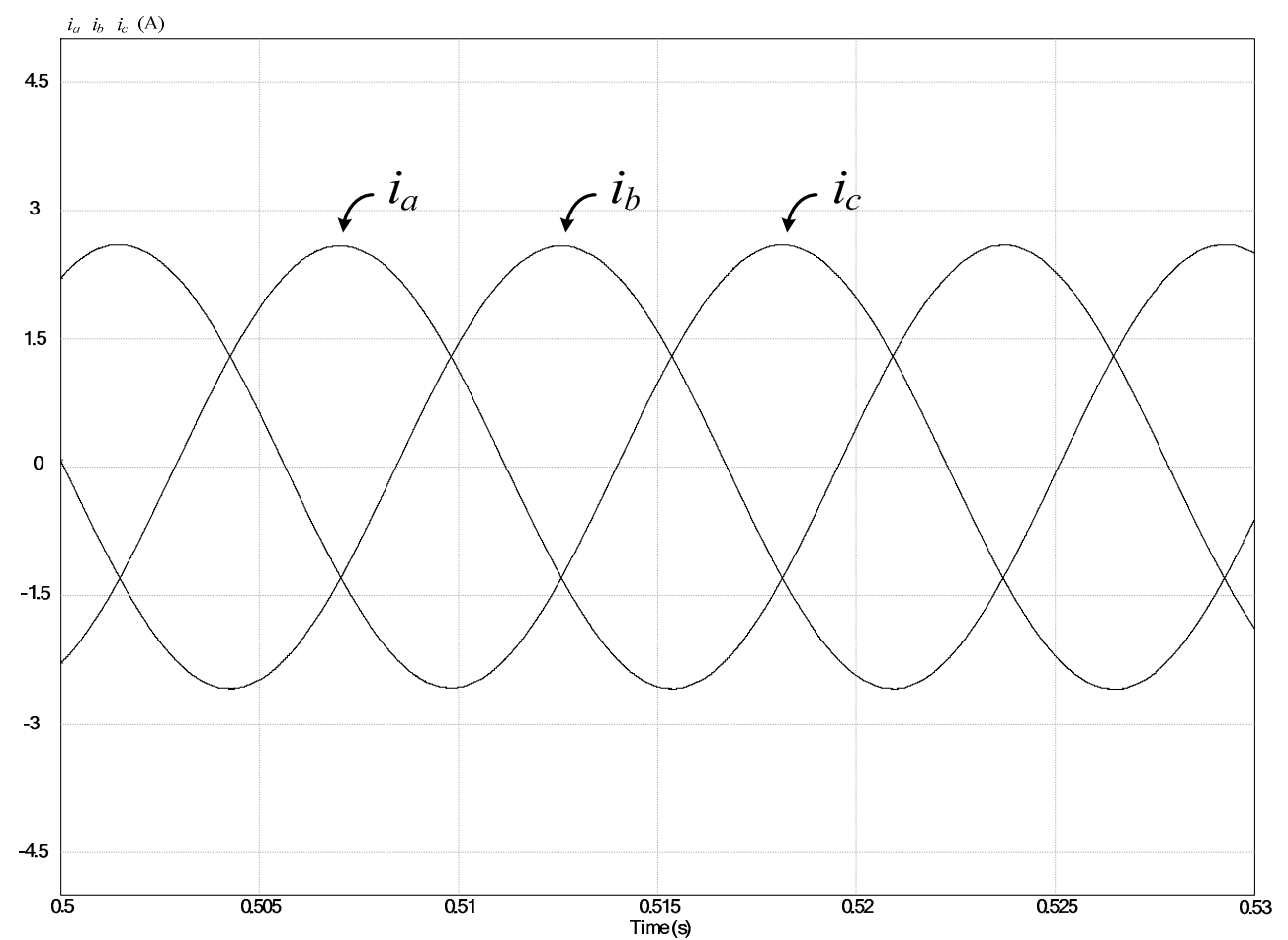

Figure 3. Output waveforms of line currents for an inverter working at $60 \mathrm{~Hz}$ without any faulty switches.

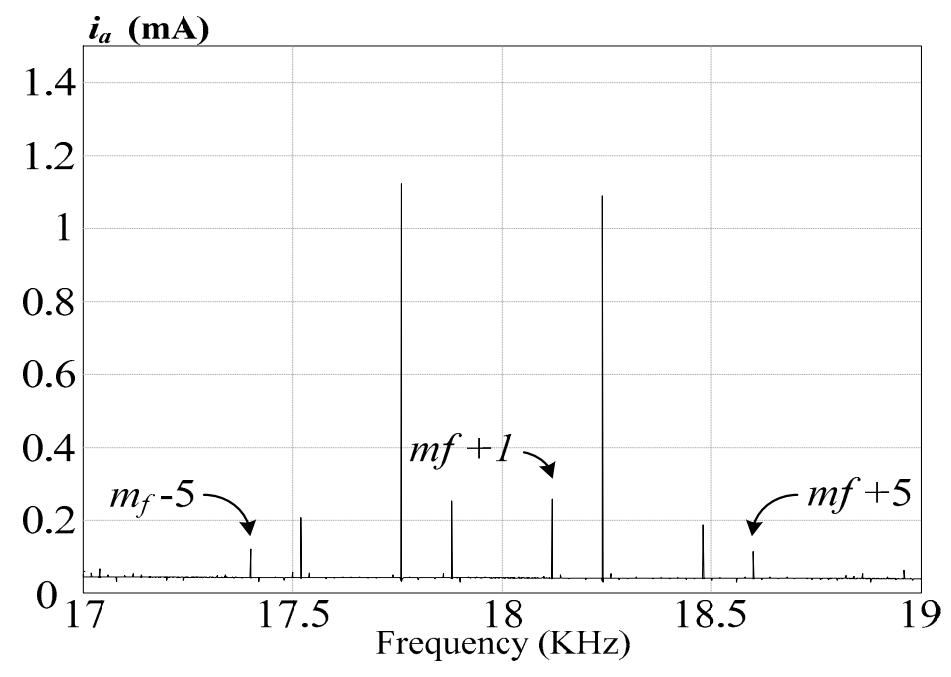

(a)

Figure 4. Cont. 


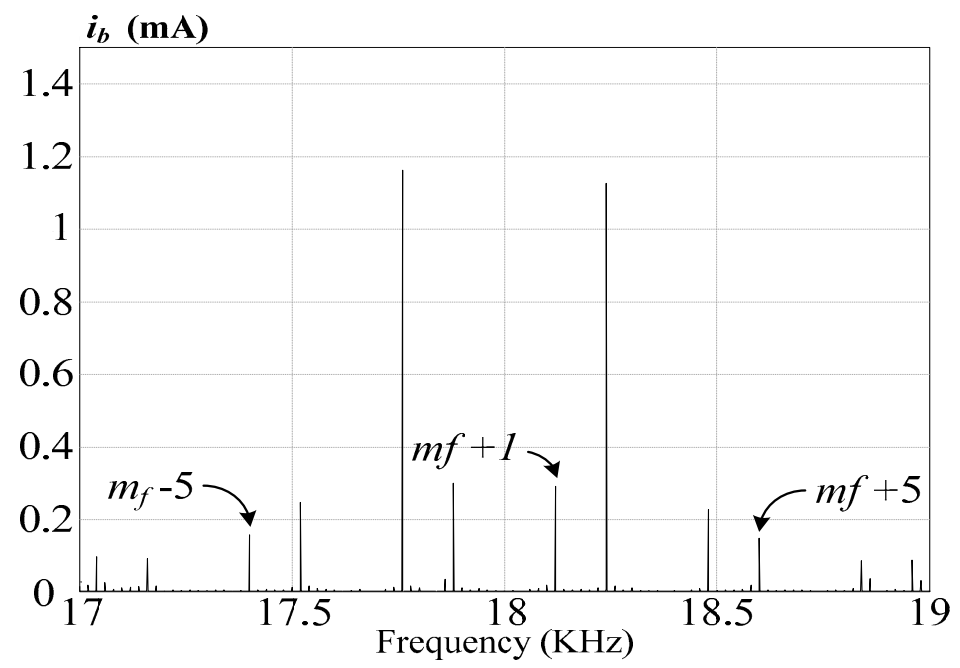

(b)

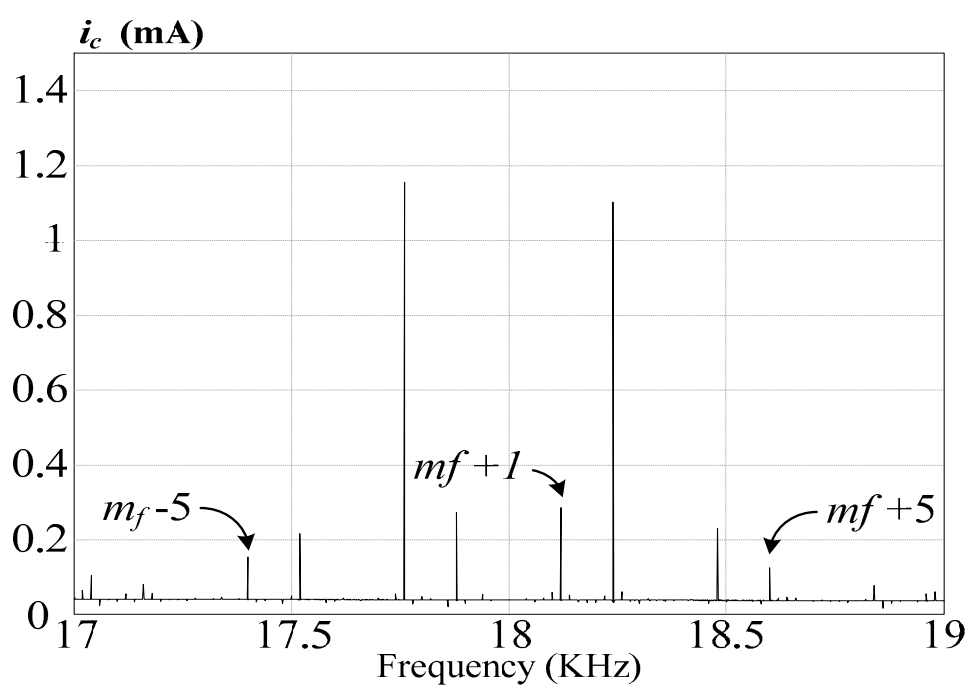

(c)

Figure 4. Frequency spectra of line currents for an inverter working at $60 \mathrm{~Hz}$ without any faulty switches: (a) line current $i_{a} ;(\mathbf{b})$ line current $i_{b} ;(\mathbf{c})$ line current $i_{c}$.

If any switch in the inverter is faulty, the characteristics of the inverter change. For instance, when a switch of the inverter $S_{a 1}{ }^{+}$is faulty, a distorted waveform of its output line current $i_{a}$ can be seen as shown in Figure 5 . Figure 6 shows the waveform of the line current $i_{b}$ with the fault inverter switch $S_{b 2}{ }^{-}$, where the waveform obviously differs from the one in normal working conditions. Figure 7 shows the waveform of the line current $i_{c}$ with the faulty switch $S_{c 2}{ }^{+}$, where the distortion is apparent. 


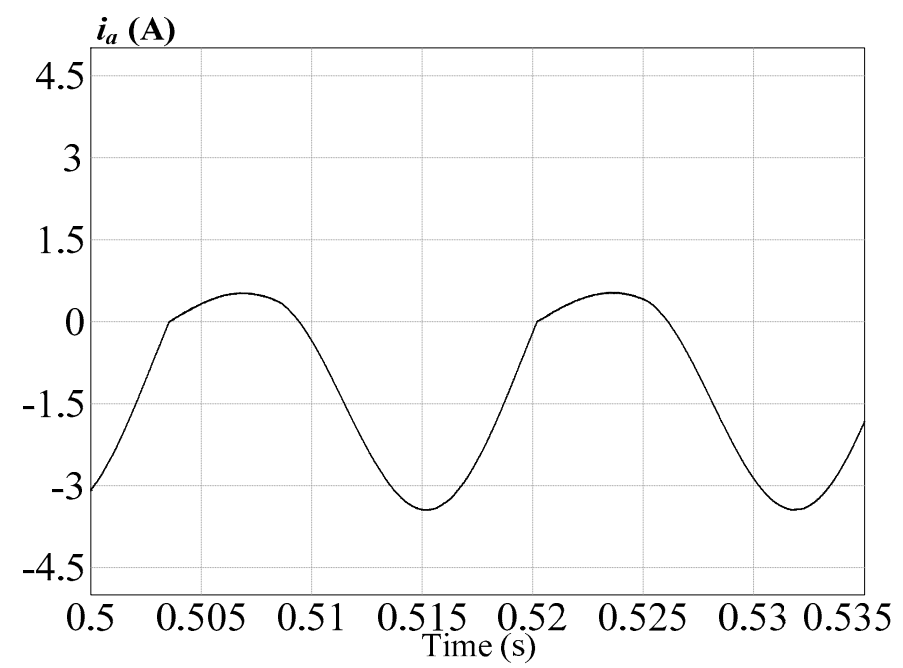

Figure 5. Waveform of line current $i_{a}$ for an inverter working at $60 \mathrm{~Hz}$ with faulty switch $S_{a 1}{ }^{+}$.

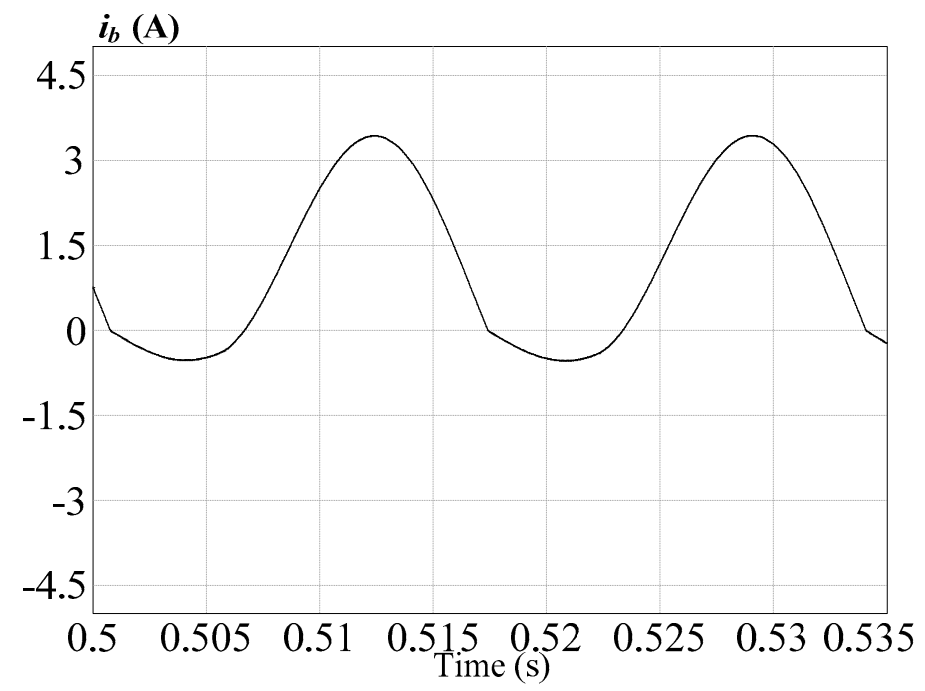

Figure 6. Waveform of line current $i_{b}$ for an inverter working at $60 \mathrm{~Hz}$ with faulty switch $S_{b 2}{ }^{-}$.

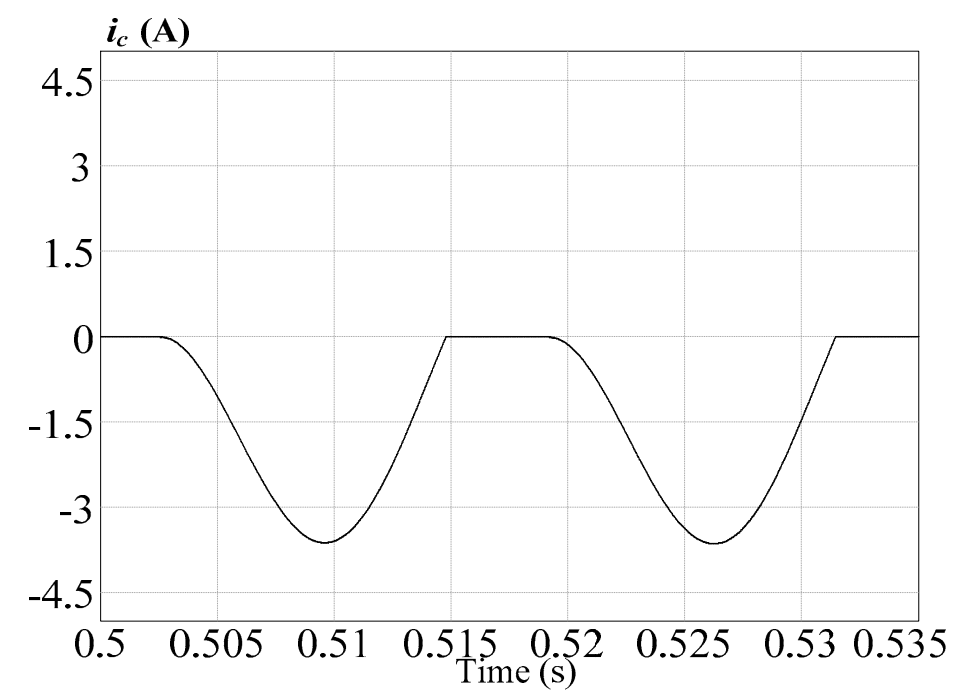

Figure 7. Waveform of line current $i_{c}$ for an inverter working at $60 \mathrm{~Hz}$ with faulty switch $S_{c_{2}}{ }^{+}$. 
It is clear from the above analysis that anomalies can be observed in current frequency spectra when an inverter is faulty, as in the case of an inverter working at $60 \mathrm{~Hz}$ with faulty switch $\mathrm{S}_{\mathrm{c2}}{ }^{+}$, where the resultant current frequency spectrum is given as shown in Figure 8. When compared with the frequency spectra without a fault in Figure 4, this demonstrates that the frequency spectrum of line current $i_{c}$ has a feature spectrum with relatively major changes at the positions of $m_{f}+1, m_{f}+5$, and $m_{f}-5$.

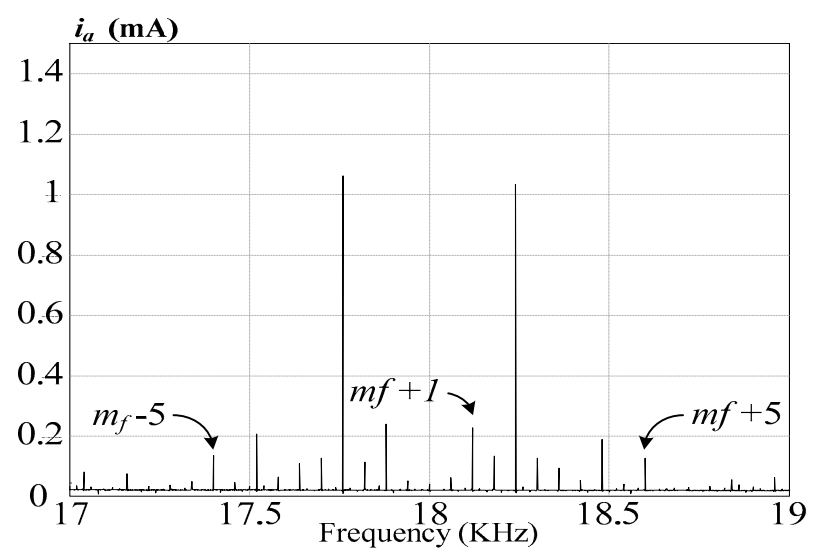

(a)

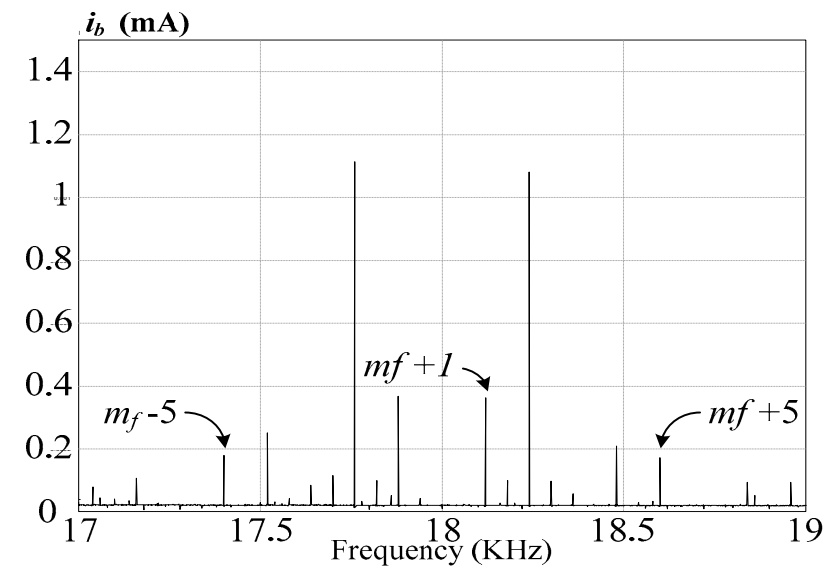

(b)

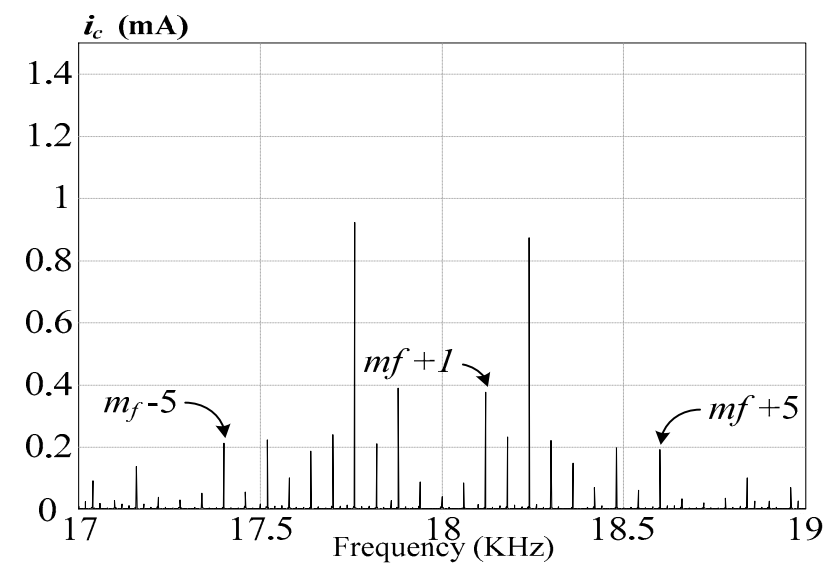

(c)

Figure 8. Frequency spectra of line currents for an inverter working at $60 \mathrm{~Hz}$ with faulty switch $\mathrm{Sc}_{2}{ }^{+}$: (a) line current $i_{a} ;(\mathbf{b})$ line current $i_{b} ;(\mathbf{c})$ line current $i_{c}$. 
Relevant data for power transistor faults can be obtained by simulation and analysis. These data can be used with extension theory to create an inverter fault diagnosis system for detecting faults in power semiconductor switches in the main circuits of three-level NPC inverters.

\section{Extension Theory}

Extension theory, which was proposed by Dr. Cai Wen in 1983, is a formalized tool for studying and solving problems with qualitative and quantitative methods [29]. The theory structurally consists of matter-element theory and extension mathematics, in which the extension theory uses logic algorithms with matter elements. The matter-element theory deals with extensibility and the change of matter elements, describes them in formalized language, and details computation and reasoning. Extension mathematics builds adaptive mathematical tools from extension sets and correlation functions. As such, extension theory creates matter-element models and uses the property transformation of matter elements for qualitative and quantitative transformation, then determining qualitative and quantitative effects via correlation functions to clearly express the effects of features.

Extension theory is a science of solving contradictory problems by dealing with extensibility and rules and methods of transformation. It features (1) the idea of changing contradictory problems into compatible ones and (2) creates matter-element theory to provide new ways of solving contradictory problems with matter-element transformation based on the extensibility of matter elements. Extension theory also (3) creates extension set theory, giving quantitative descriptions of quantitative change to qualitative changes in the extension domain and critical elements, thus realizing quantitative extension mathematics in the extension theory based on extension sets [26-30].

\subsection{Basic Concept of Extension Matter-Element Theory}

In dealing with contradictory problems, if concepts, characteristics, and their corresponding data are brought together for consideration, it is possible to deduce problem solving methods. Hence, the concept of "matter elements" was introduced [30], which consists of "name" and "characteristic" of a matter and the "value" that corresponds to the characteristic. Matter elements are the basic elements in extension theory that describe matters, denoted by $R, N$ (name), $c$ (characteristic), and $v$ (value) as an expression as follows:

$$
R=(N, c, v)
$$

Additionally, via the above definition for a matter element, the correlation between the characteristics of these three basic elements and the corresponding value can be expressed by the equation below:

$$
v=c(N)
$$

Thus, Equation (2) for a matter element is converted into the following form:

$$
R=(N, c, c(N))
$$

To understand the relationships between basic matter elements, references can be made to the expression by a space of matter elements, as Figure 9 shows, where the name, characteristic, and value are plotted in the $x$-, $y$ - and $z$-axes, which also displays the feature of the change of such a combination. 


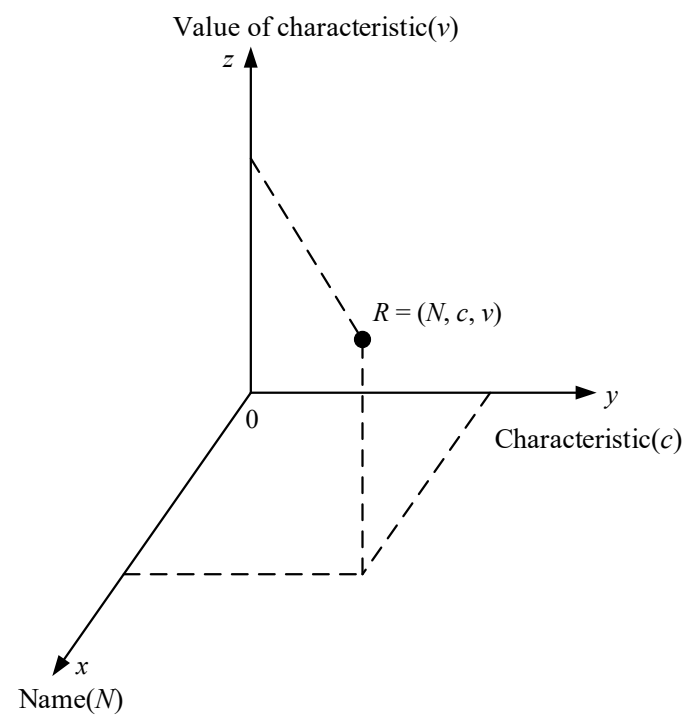

Figure 9. Space of matter elements.

Furthermore, in extension matter-element theory, if the matter elements have multiple characteristics, they can be expressed by $\mathrm{m}$ characteristics, i.e., $c_{1}, c_{2}, \ldots c_{m}$, and $\mathrm{m}$ corresponds to the values of characteristics, i.e., $v_{1}, v_{2}, \ldots v_{m}$, in an equation for their correlations as follows:

$$
R=\left[\begin{array}{ccc}
N, & c_{1}, & v_{1} \\
& c_{2}, & v_{2} \\
& \cdots & \ldots \\
& c_{m}, & v_{m}
\end{array}\right]=\left[\begin{array}{c}
R_{1} \\
R_{2} \\
\ldots \\
R_{m}
\end{array}\right]
$$

In Equation (5), $R$ is called an $m$-dimensional matter element, whose components are expressed by $R_{k}=\left(N, c_{k}, v_{k}\right)(k=1,2, \ldots, m)$. Thus, Equation (5) can be rewritten as $R=(N, C, V)$, where matrix $C=\left[c_{1}, c_{2}, \ldots c_{m}\right]^{T}$ and matrix $V=\left[v_{1}, v_{2}, \ldots v_{m}\right]^{T}$. Therefore, by the way of a multi-dimensional definition, it enables describing any single thing in the real world.

The characteristic value corresponding to a characteristic can be a single point or a single range. In the latter case, such a range is referred to as a classical domain which is contained in a neighborhood domain. Assume point $\mathrm{f}$ is any point in the interval $F=\left\langle a_{q}, b_{q}\right\rangle$, and $F_{0} \in F$, then, the matter element, $R_{0}$, corresponded by $\left.F_{0}=<a_{p}, b_{p}\right\rangle$ can be expressed by Equation (6), where $C$ is a characteristic and $V_{p}$ is the value for $C$, i.e., its classical domain:

$$
\begin{aligned}
R_{0} & =\left(F_{0}, C, V_{p}\right) \\
& =\left[\begin{array}{ccc}
F_{0}, & c_{1}, & V_{\mathrm{p} 1} \\
& c_{2}, & V_{\mathrm{p} 2} \\
& \vdots & \vdots \\
& c_{m}, & V_{\mathrm{p} m}
\end{array}\right] \\
& =\left[\begin{array}{ccc}
F_{0}, & c_{1}, & <a_{p 1}, b_{p 1}> \\
& c_{2}, & <a_{p 2}, b_{p 2}> \\
\vdots & \vdots \\
c_{m}, & <a_{p m}, b_{p m}>
\end{array}\right]
\end{aligned}
$$


A matter element, $R_{F}$, corresponded by $F$, can be expressed by Equation (7). Similarly, $C$ is the value of the characteristic for $F$ and $V_{q}$ is the value for $C$, i.e., its neighborhood domain:

$$
\begin{aligned}
R_{F} & =\left(F, C, V_{q}\right) \\
& =\left[\begin{array}{ccc}
F, & c_{1}, & V_{\mathrm{q} 1} \\
& c_{2}, & V_{\mathrm{q} 2} \\
\vdots & \vdots \\
& c_{m}, & V_{\mathrm{q} m}
\end{array}\right] \\
& =\left[\begin{array}{ccc}
F, & c_{1}, & <a_{q 1}, b_{q 1}> \\
c_{2}, & <a_{q 2}, b_{q 2}> \\
\vdots & \vdots \\
c_{m}, & <a_{q m}, b_{q m}>
\end{array}\right]
\end{aligned}
$$

\subsection{Correlation Function}

If $F_{0} \in F$, then the correlation function $K(f)$ can be defined as follows:

$$
K(f)=\frac{\rho\left(f, F_{0}\right)}{D\left(f, F_{0}, F\right)}
$$

If set $K(f) \leq 1$, then:

$$
\begin{array}{r}
\rho\left(f, F_{0}\right)=\left|f-\frac{a_{p}+b_{p}}{2}\right|-\frac{b_{p}-a_{p}}{2} \\
D\left(f, F_{0}, F\right)= \begin{cases}\rho(f, F)-\rho\left(f, F_{0}\right) & f \notin F_{0} \\
-\frac{\left|\left(a_{p}-b_{p}\right)\right|}{2} & f \in F_{0}\end{cases}
\end{array}
$$

where:

$$
\rho(f, F)=\left|f-\frac{a_{q}+b_{q}}{2}\right|-\frac{b_{q}-a_{q}}{2}
$$

Correlation functions can be used to determine the membership grade between $f$ and $F_{0}$. Extension correlation functions are given in Figure 10. The figure indicates that if $K(f)>0$, it means that point $f$ currently lies within domain $F_{0}$. If $K(f)<-1$, it means point $f$ will not be within either of the two domains, and if $-1 \leq K(f) \leq 0$, it means that the point lies not within domain $F_{0}$, but within domain $F$. In extension domains, it is possible to make use of transformation of conditions such that $f$ can belong to the domain of $F_{0}$.

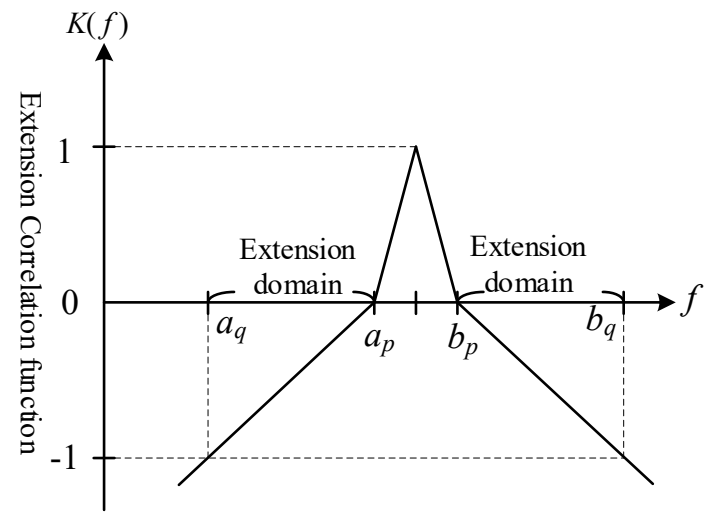

Figure 10. The curve for the correlation function. 


\section{Extension Theory-Based Fault Diagnosis for Inverters}

The inverter fault diagnosis system operates when a switch fails to actuate normally as a result of having worked in over-current or high-temperature conditions for an extended period of time or after aging, among other causes. Hence, the present research considers testing switch faults with the framework for three-level NPC inverters as shown in Figure 2, where the positions of faulty transistors are identified by extension theory.

To begin with, the waveforms of the line currents in three phases on the inverter under simulation were subjected to fast Fourier transformation (FFT) to generate the feature frequency spectra for the line currents at $m_{f}+1, m_{f}+5$, and $m_{f}-5$ as input signals in the fault diagnosis system that were built based on extension theory. The faults were divided into 12 types by switches $S_{a 1}{ }^{+}, S_{a 2}{ }^{+}, S_{a 1}{ }^{-}, S_{a 2}{ }^{-}$, $S_{b 1}{ }^{+}, S_{b 2}{ }^{+}, S_{b 1}{ }^{-}, S_{b 2}{ }^{-}, S_{c 1}{ }^{+}, S_{c 2}{ }^{+}, S_{c 1}{ }^{-}$, and $S_{c 2}{ }^{-}$.

Additionally, from the 84 records for the feature frequency spectra that were measured with twelve different switch faults with the inverter working at a frequency range of $30-90 \mathrm{~Hz}$, and additionally based on the values for the feature frequency spectra of the twelve fault types, the upper and lower limits for the neighborhood domains in each fault type were identified. The classical domains were further set by the feature frequency spectra of each fault type.

The diagnosis and identification process for inverter faults with extension theory is delineated as follows:

Step 1: Create a matter-element model for fault characteristics $C_{1}, C_{2}$, and $C_{3}$ on the frequency spectra for the line current for each fault type.

$$
R_{g}=\left(F, C, V_{p}\right)=\left[\begin{array}{lll}
F_{0} & C_{1} & <x_{1}, \mathrm{y}_{1}> \\
& C_{2} & <x_{2}, \mathrm{y}_{2}> \\
& C_{3} & <x_{3}, \mathrm{y}_{3}>
\end{array}\right], \mathrm{g}=1,2, \ldots, 12
$$

Step 2: Input uncategorized fault characteristics $C_{1}, C_{2}$, and $C_{3}$ with the frequency spectra of the line current to create a matter-element model.

$$
R_{\text {new }}=\left[\begin{array}{ccc}
F_{\text {new }} & C_{1} & V_{\text {new } 1} \\
& C_{2} & V_{\text {new } 2} \\
& C_{3} & V_{\text {new } 3}
\end{array}\right]
$$

Step 3: Assign weights to the characteristics of each fault type $\left(W_{1}, W_{2}\right.$, and $\left.W_{3}\right)$ which represent the significance of these characteristics. Set $W_{1}=W_{2}=W_{3}=1 / 3$ here.

Step 4: Calculate the correlation between uncategorized fault characteristics on the frequency spectra of the line current and each existing fault type.

$$
\lambda_{g}=\sum_{j=1}^{3} W_{j} K_{g}, g=1,2, \ldots, 12
$$

Step 5: The maximum correlation value from the calculation determines the category of the uncategorized fault characteristics $C_{1}, C_{2}$, and $C_{3}$ on the frequency spectra of the line current. Thus, the fault type is identified.

\section{Test Results}

In order to identify faulty power transistors, all the fault types were divided into 12 switch fault conditions, i.e., $S_{a 1}{ }^{+}, S_{a 2}{ }^{+}, S_{a 1}{ }^{-}, S_{a 2}{ }^{-}, S_{b 1}{ }^{+}, S_{b 2}{ }^{+}, S_{b 1}{ }^{-}, S_{b 2}{ }^{-}, S_{c 1}{ }^{+}, S_{c 2}{ }^{+}, S_{c 1}{ }^{-}$, and $S_{c 2}{ }^{-}$, as shown in Table 1. 
Table 1. Types of fault diagnosis.

\begin{tabular}{cc}
\hline Fault Condition & Type \\
\hline A faulty $S_{a 1}{ }^{+}$switch & $F_{1}$ \\
A faulty $S_{a 2}{ }^{+}$switch & $F_{2}$ \\
A faulty $S_{a 1}{ }^{-}$switch & $F_{3}$ \\
A faulty $S_{a 2^{-}}$switch & $F_{4}$ \\
A faulty $S_{b 1}{ }^{+}$switch & $F_{5}$ \\
A faulty $S_{b 2}{ }^{+}$switch & $F_{6}$ \\
A faulty $S_{b 1}{ }^{-}$switch & $F_{7}$ \\
A faulty $S_{b 2}{ }^{-}$switch & $F_{8}$ \\
A faulty $S_{c 1}{ }^{+}$switch & $F_{9}$ \\
A faulty $S_{c 2}{ }^{+}$switch & $F_{10}$ \\
A faulty $S_{c 1}{ }^{-}$switch & $F_{11}$ \\
A faulty $S_{c 2}{ }^{-}$switch & $F_{12}$ \\
\hline
\end{tabular}

Tables 2 and 3 show the data for the characteristic frequency spectra of the line currents with a faulty switch working at 40 and $80 \mathrm{~Hz}$. These measured data were used as inputs in the fault diagnosis system, generating the results of identification shown in Tables 4 and 5. The two tables indicate that the data for every fault were accurately identified. For example, considering $F_{5}$ in the test data in Table 2, it is clear from the identification results in Table 4 that $F_{5}$ was determined according to the highest output correlation at 0.78784 , while the correlation $F_{12}$ was the lowest at -0.33376 , which suggests that $F_{12}$ was least likely.

Table 2. Data for feature frequency spectra for faulty switches in an inverter working at $40 \mathrm{~Hz}$.

\begin{tabular}{|c|c|c|c|c|c|c|c|c|c|}
\hline \multirow{2}{*}{ Fault Type } & \multicolumn{3}{|c|}{$\begin{array}{c}i_{a} \text { Characteristic Frequency } \\
\text { Spectrum (mA) }\end{array}$} & \multicolumn{3}{|c|}{$\begin{array}{c}i_{b} \text { Characteristic Frequency } \\
\text { Spectrum (mA) }\end{array}$} & \multicolumn{3}{|c|}{$\begin{array}{c}i_{c} \text { Characteristic Frequency } \\
\text { Spectrum (mA) }\end{array}$} \\
\hline & $m_{f}+1$ & $m_{f}+5$ & $m_{f}-5$ & $m_{f}+1$ & $m_{f}+5$ & $m_{f}-5$ & $m_{f}+1$ & $m_{f}+5$ & $m_{f}-5$ \\
\hline$F_{1}$ & 0.59 & 0.14 & 0.15 & 0.26 & 0.11 & 0.11 & 0.33 & 0.03 & 0.06 \\
\hline$F_{2}$ & 0.43 & 0.26 & 0.23 & 0.17 & 0.13 & 0.14 & 0.26 & 0.14 & 0.10 \\
\hline$F_{3}$ & 0.37 & 0.28 & 0.27 & 0.22 & 0.13 & 0.10 & 0.15 & 0.16 & 0.18 \\
\hline$F_{4}$ & 0.56 & 0.21 & 0.22 & 0.31 & 0.06 & 0.07 & 0.26 & 0.15 & 0.15 \\
\hline$F_{5}$ & 0.26 & 0.10 & 0.11 & 0.58 & 0.23 & 0.21 & 0.30 & 0.16 & 0.13 \\
\hline$F_{6}$ & 0.21 & 0.10 & 0.11 & 0.32 & 0.31 & 0.33 & 0.12 & 0.22 & 0.21 \\
\hline$F_{7}$ & 0.13 & 0.20 & 0.20 & 0.36 & 0.28 & 0.28 & 0.24 & 0.08 & 0.08 \\
\hline$F_{8}$ & 0.32 & 0.13 & 0.12 & 0.56 & 0.20 & 0.21 & 0.26 & 0.10 & 0.13 \\
\hline$F_{9}$ & 0.31 & 0.08 & 0.07 & 0.28 & 0.10 & 0.11 & 0.59 & 0.19 & 0.18 \\
\hline$F_{10}$ & 0.19 & 0.14 & 0.14 & 0.18 & 0.13 & 0.15 & 0.37 & 0.27 & 0.27 \\
\hline$F_{11}$ & 0.20 & 0.11 & 0.17 & 0.19 & 0.11 & 0.14 & 0.39 & 0.22 & 0.28 \\
\hline$F_{12}$ & 0.22 & 0.14 & 0.14 & 0.25 & 0.11 & 0.09 & 0.48 & 0.26 & 0.29 \\
\hline
\end{tabular}

Table 3. Data for feature frequency spectra for faulty switches in an inverter working at $80 \mathrm{~Hz}$.

\begin{tabular}{|c|c|c|c|c|c|c|c|c|c|}
\hline \multirow[t]{2}{*}{ Fault Type } & \multicolumn{3}{|c|}{$\begin{array}{c}i_{a} \text { Characteristic Frequency } \\
\text { Spectrum (mA) }\end{array}$} & \multicolumn{3}{|c|}{$\begin{array}{c}i_{b} \text { Characteristic Frequency } \\
\text { Spectrum (mA) }\end{array}$} & \multicolumn{3}{|c|}{$\begin{array}{c}i_{c} \text { Characteristic Frequency } \\
\text { Spectrum (mA) }\end{array}$} \\
\hline & $m_{f}+1$ & $m_{f}+5$ & $m_{f}-5$ & $m_{f}+1$ & $m_{f}+5$ & $m_{f}-5$ & $m_{f}+1$ & $m_{f}+5$ & $m_{f}-5$ \\
\hline$F_{1}$ & 0.59 & 0.13 & 0.14 & 0.28 & 0.08 & 0.08 & 0.3 & 0.05 & 0.06 \\
\hline$F_{2}$ & 0.25 & 0.24 & 0.24 & 0.12 & 0.12 & 0.12 & 0.13 & 0.12 & 0.11 \\
\hline$F_{3}$ & 0.19 & 0.28 & 0.30 & 0.11 & 0.12 & 0.13 & 0.07 & 0.16 & 0.16 \\
\hline$F_{4}$ & 0.55 & 0.19 & 0.19 & 0.28 & 0.08 & 0.08 & 0.26 & 0.11 & 0.10 \\
\hline$F_{5}$ & 0.26 & 0.09 & 0.10 & 0.55 & 0.20 & 0.20 & 0.29 & 0.12 & 0.11 \\
\hline$F_{6}$ & 0.11 & 0.12 & 0.13 & 0.17 & 0.31 & 0.31 & 0.07 & 0.19 & 0.19 \\
\hline$F_{7}$ & 0.07 & 0.19 & 0.18 & 0.17 & 0.31 & 0.31 & 0.11 & 0.12 & 0.13 \\
\hline$F_{8}$ & 0.29 & 0.13 & 0.11 & 0.55 & 0.20 & 0.20 & 0.26 & 0.09 & 0.10 \\
\hline$F_{9}$ & 0.30 & 0.08 & 0.07 & 0.26 & 0.10 & 0.11 & 0.56 & 0.18 & 0.17 \\
\hline$F_{10}$ & 0.10 & 0.15 & 0.14 & 0.10 & 0.13 & 0.15 & 0.19 & 0.27 & 0.29 \\
\hline$F_{11}$ & 0.09 & 0.14 & 0.17 & 0.10 & 0.13 & 0.14 & 0.19 & 0.27 & 0.32 \\
\hline$F_{12}$ & 0.23 & 0.12 & 0.14 & 0.27 & 0.09 & 0.09 & 0.51 & 0.21 & 0.23 \\
\hline
\end{tabular}


Table 4. Results for the identification of different switch faults in an inverter working at $40 \mathrm{~Hz}$.

\begin{tabular}{|c|c|c|c|c|c|c|c|c|c|c|c|c|c|}
\hline Fault Type & $F_{1}$ & $F_{2}$ & $F_{3}$ & $F_{4}$ & $F_{5}$ & $F_{6}$ & $F_{7}$ & $F_{8}$ & $F_{9}$ & $F_{10}$ & $F_{11}$ & $F_{12}$ & Identification Result \\
\hline$F_{1}$ & 0.559732 & -0.2341 & -0.30163 & -0.25791 & -0.35161 & -0.28997 & -0.28827 & -0.37557 & -0.13128 & -0.19571 & -0.09069 & 0.122352 & $F_{1}$ \\
\hline$F_{2}$ & -0.31894 & 0.529985 & 0.19564 & 0.101215 & -0.24656 & -0.39278 & -0.13254 & -0.18231 & -0.38297 & -0.06586 & -0.03606 & -0.39277 & $F_{2}$ \\
\hline$F_{3}$ & -0.32544 & 0.153303 & 0.480904 & -0.28298 & -0.35341 & -0.24157 & -0.23005 & -0.45123 & -0.15916 & -0.30098 & -0.31193 & -0.30453 & $F_{3}$ \\
\hline$F_{4}$ & -0.19607 & -0.02785 & -0.05336 & 0.669501 & -0.25911 & -0.38318 & -0.191 & -0.29812 & -0.35435 & -0.31991 & -0.25472 & -0.35481 & $F_{4}$ \\
\hline$F_{5}$ & -0.30139 & -0.1844 & -0.11302 & -0.27134 & 0.78784 & -0.14891 & -0.31367 & 0.170666 & -0.27814 & -0.28528 & -0.1707 & -0.33376 & $F_{5}$ \\
\hline$F_{6}$ & -0.5183 & -0.40867 & -0.23671 & -0.5169 & -0.1806 & 0.410636 & -0.05613 & -0.31277 & -0.3506 & -0.35322 & -0.1498 & -0.15425 & $F_{6}$ \\
\hline$F_{7}$ & -0.35259 & -0.12849 & -0.3183 & -0.11627 & -0.33122 & -0.09984 & 0.386716 & -0.25002 & -0.54508 & -0.20199 & -0.1635 & -0.48438 & $F_{7}$ \\
\hline$F_{8}$ & -0.19771 & -0.04102 & -0.25002 & -0.07334 & 0.370901 & -0.22944 & -0.12948 & 0.729028 & -0.28932 & -0.14899 & -0.15479 & -0.23812 & $F_{8}$ \\
\hline$F_{9}$ & -0.10774 & -0.24794 & -0.13496 & -0.26971 & -0.19914 & -0.13057 & -0.42272 & -0.2614 & 0.729557 & -0.40752 & -0.27084 & -0.06767 & $F_{9}$ \\
\hline$F_{10}$ & -0.21181 & -0.04626 & 0.010629 & -0.39599 & -0.31255 & -0.06477 & -0.34739 & -0.33145 & -0.31563 & 0.35106 & 0.337094 & 0.172031 & $F_{10}$ \\
\hline$F_{11}$ & -0.20393 & -0.17468 & -0.14651 & -0.38417 & -0.24391 & 0.13807 & -0.3556 & -0.2593 & -0.17523 & 0.138607 & 0.454056 & 0.202084 & $F_{11}$ \\
\hline$F_{12}$ & -0.11796 & -0.17041 & -0.18303 & -0.36593 & -0.38078 & -0.13336 & -0.31591 & -0.39715 & -0.15802 & 0.096222 & 0.373375 & 0.5391 & $F_{12}$ \\
\hline
\end{tabular}

Table 5. Results for the identification of different switch faults in an inverter working at $80 \mathrm{~Hz}$.

\begin{tabular}{|c|c|c|c|c|c|c|c|c|c|c|c|c|c|}
\hline Fault Type & $F_{1}$ & $F_{2}$ & $F_{3}$ & $F_{4}$ & $F_{5}$ & $F_{6}$ & $F_{7}$ & $F_{8}$ & $F_{9}$ & $F_{10}$ & $F_{11}$ & $F_{12}$ & Identification Result \\
\hline$F_{1}$ & 0.622689 & -0.34653 & -0.43611 & -0.06351 & -0.32677 & -0.28556 & -0.30873 & -0.27985 & -0.34084 & -0.23062 & -0.18383 & -0.13332 & $F_{1}$ \\
\hline$F_{2}$ & -0.38422 & 0.592683 & 0.4343 & -0.09045 & -0.25795 & -0.38591 & -0.06168 & -0.31945 & -0.35681 & -0.21063 & -0.05411 & -0.33311 & $F_{2}$ \\
\hline$F_{3}$ & -0.58218 & -0.28377 & 0.547845 & -0.56388 & -0.3993 & -0.3059 & -0.50629 & -0.56016 & -0.41968 & -0.28528 & -0.13195 & -0.44254 & $F_{3}$ \\
\hline$F_{4}$ & 0.06017 & 0.043765 & -0.23491 & 0.561843 & -0.33158 & -0.35213 & 0.19983 & -0.17871 & -0.29778 & -0.28035 & -0.17302 & -0.29794 & $F_{4}$ \\
\hline$F_{5}$ & -0.36619 & -0.07315 & -0.25264 & -0.24308 & 0.585479 & -0.27545 & -0.20206 & 0.325634 & -0.21915 & -0.27345 & -0.18597 & -0.38598 & $F_{5}$ \\
\hline$F_{6}$ & -0.46206 & -0.39656 & -0.16292 & -0.52598 & -0.31768 & 0.599934 & 0.122139 & -0.29312 & -0.27273 & -0.14926 & -0.08569 & -0.31517 & $F_{6}$ \\
\hline$F_{7}$ & -0.50241 & -0.04344 & -0.06313 & -0.13996 & -0.31732 & 0.130542 & 0.403082 & -0.39168 & -0.55918 & -0.37664 & -0.19821 & -0.52746 & $F_{7}$ \\
\hline$F_{8}$ & -0.18896 & -0.09863 & -0.27318 & -0.18287 & 0.249617 & -0.28389 & -0.10745 & 0.686704 & -0.36196 & -0.19957 & -0.1727 & -0.25936 & $F_{8}$ \\
\hline$F_{10}$ & -0.39289 & -0.05756 & -0.16112 & -0.47144 & -0.42423 & -0.19086 & -0.21326 & -0.40214 & -0.47384 & 0.664821 & 0.341783 & -0.13587 & $F_{10}$ \\
\hline$F_{11}$ & -0.34599 & -0.00483 & -0.19398 & -0.4578 & -0.50207 & -0.32113 & -0.22635 & -0.47022 & -0.51012 & 0.347249 & 0.458702 & -0.19029 & $F_{11}$ \\
\hline$F_{12}$ & 0.1033 & -0.28286 & -0.18499 & -0.22448 & -0.27963 & 0.12889 & -0.33649 & -0.22669 & 0.053569 & -0.15907 & 0.002915 & 0.446516 & $F_{12}$ \\
\hline
\end{tabular}




\section{Fault-Tolerant Control for Three-Level NPC Inverters}

\subsection{Analysis of Tolerant Control}

The switch faults of a three-level NPC inverter are divided into two types: external switch faults and internal switch faults. In the framework of a three-level NPC inverter in Figure 2, if any of the external switches $\mathrm{S} a 1^{+}, \mathrm{S} a 2^{-}, \mathrm{S} b 1^{+}, \mathrm{S} b 2^{-}, \mathrm{S} c 1^{+}$, and $\mathrm{Sc} 2^{-}$are faulty because of an open circuit, then it is necessary to alter both the switching condition of the inverter and the phase angle of sine reference voltage in the pulse width modulation (PWM) control signals to keep the output voltage of the inverter in a balanced three-phase form. The parameters of the induction motor are listed in Table 6.

Table 6. Parameter of the three-phase inductor motor.

\begin{tabular}{ccccccc}
\hline $\begin{array}{c}\text { Horsepower } \\
(\mathbf{H p})\end{array}$ & $\begin{array}{c}\text { Rotor } \\
\text { Resistance } \\
(\boldsymbol{\Omega})\end{array}$ & $\begin{array}{c}\text { Rotor } \\
\text { Leakage } \\
\text { Inductance } \\
\mathbf{( H )}\end{array}$ & $\begin{array}{c}\text { Stator } \\
\text { Resistance } \\
(\boldsymbol{\Omega})\end{array}$ & $\begin{array}{c}\text { Stator } \\
\text { Leakage } \\
\text { Inductance } \\
\mathbf{( H )}\end{array}$ & $\begin{array}{c}\text { Magnetization } \\
\text { Inductance } \\
\mathbf{( H )}\end{array}$ & $\begin{array}{c}\text { Moment } \\
\text { of Inertia } \\
\left(\mathbf{k g}-\mathbf{m}^{\mathbf{2}}\right)\end{array}$ \\
\hline 1 & 10.4 & 0.04 & 11.6 & 0.04 & 0.557 & 0.004 \\
\hline
\end{tabular}

\subsubsection{Tolerant Control Strategy for External Switch Faults}

When an external switch, for example $S_{a 1}{ }^{+}$or $S_{a 2}{ }^{-}$, encounters an open-circuit fault, the $a$-phase half-bridge switches $\left(S_{a 1}{ }^{+}\right.$and $\left.S_{a 2}{ }^{-}\right)$must be deactivated to activate the internal (neutral-point) switches $\left(S_{a 1}{ }^{-}\right.$and $\left.S_{a 2}{ }^{+}\right)$. Specifically, point $a$ is connected to the neutral point and $b$ - and $c$-phase are still switched normally. The fault-tolerant control for the occurrence of an open-circuit fault in $S_{a 1}{ }^{+}$is shown in Figure 11. The voltage phasor diagram corresponding to this situation is illustrated in Figure 12a. As illustrated in the figure, the phasor positions of the line voltages Vab and Vca without any switch fault in Figure 11 become those of Vab1 and Vca1, with the voltage magnitude decreasing by 0.577 times relative to the original line voltage. The line voltage $\mathbf{V b c 1}$ remains unchanged; however, because the voltage $v_{a o}$ is 0 , the phase angle of the $b$-phase voltage should be simultaneously adjusted to be $150^{\circ}$ behind that of the $a$-phase voltage, and the phase angle of the $c$-phase voltage should be $150^{\circ}$ ahead of that of the $a$-phase voltage. After the occurrence of a fault, the three-phase voltage can still maintain the operation of the balanced three-phase system and the corresponding voltage phasor diagram of the system is shown in Figure 12b. The phasor positions of the line voltages Vab1 and Vca1 presented in Figure 12a shift to those of Vab2 and Vca2, with the magnitude of the line voltage Vbc2 decreasing by 0.577 times relative to that of the original line voltage $\mathbf{V b c 1}$. Considering switch $\mathrm{S}_{a 1}{ }^{+}$ with an open-circuit fault as an example, the waveforms of the sine reference voltages in three phases are shown in Figure 13.

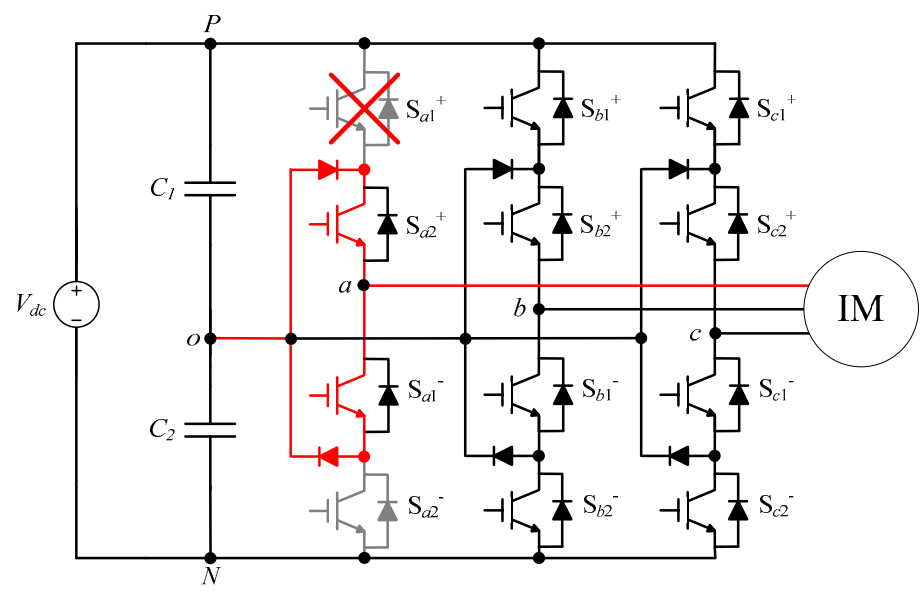

Figure 11. Fault-tolerant control for the occurrence of an open-circuit fault in $S_{a 1}{ }^{+}$. 


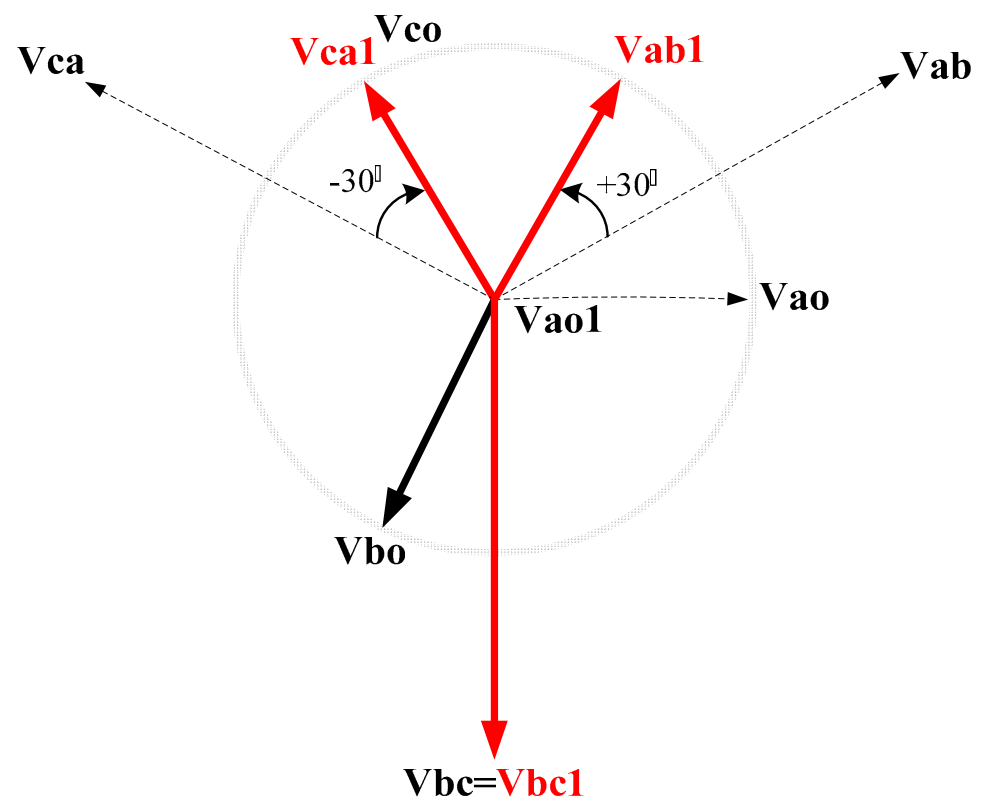

(a)

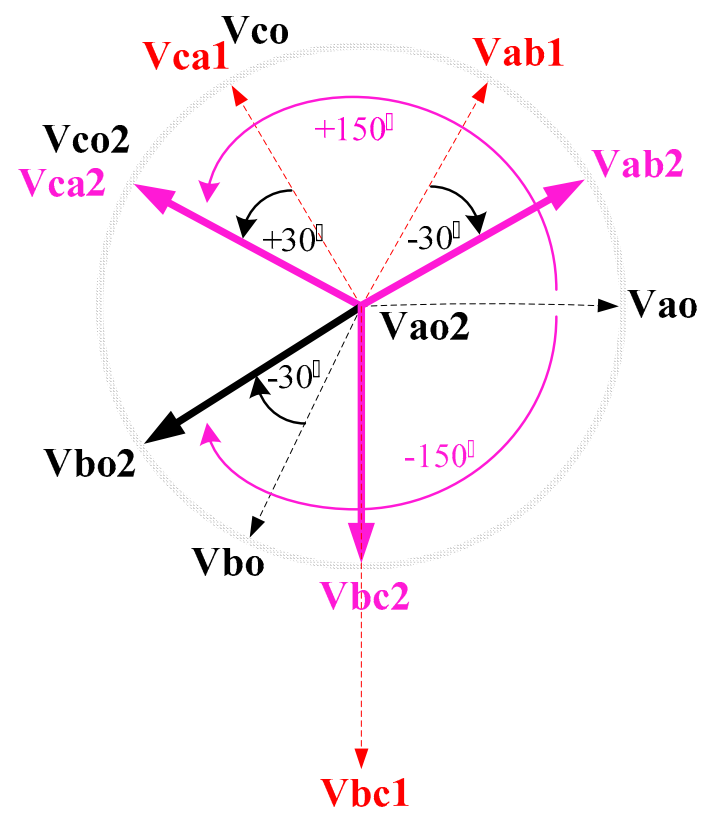

(b)

Figure 12. Voltage phasor diagram of fault-tolerant control when a fault occurs in the switch $S_{a 1}{ }^{+}$: (a) unadjusted voltage phase angle; (b) adjusted phase angle of the b-phase voltage such that it is $150^{\circ}$ behind that of the $a$-phase voltage; adjusted phase angle of the c-phase voltage such that it is $150^{\circ}$ ahead of that of the $a$-phase voltage. 


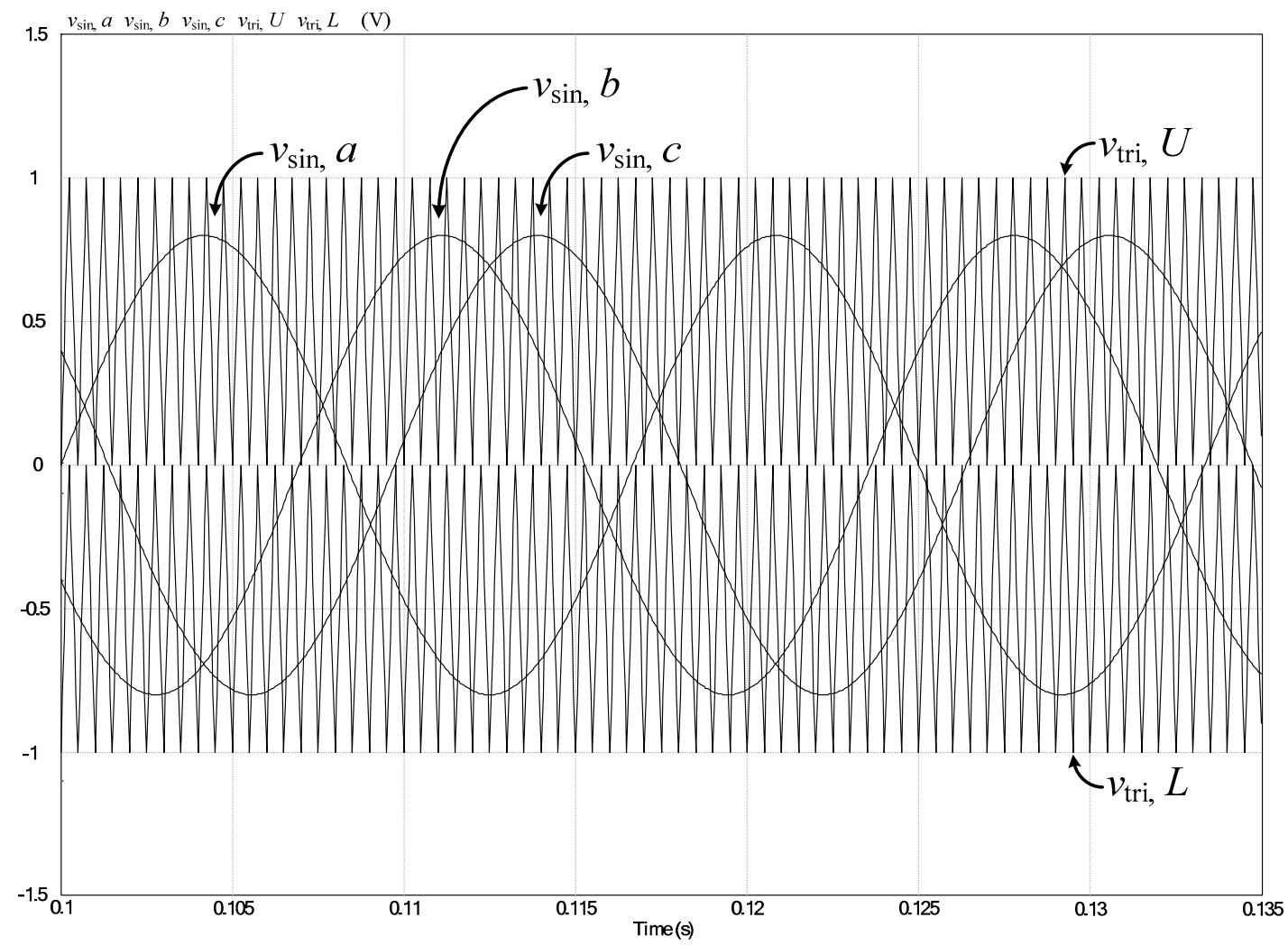

Figure 13. The waveform of pulse width modulation (PWM) control signals for the case of inverter switch $\mathrm{S} a 1^{+}$with an open-circuit fault.

Analysis of the tolerant control strategy for other external switch failures shows the same results and is not be repeated here for the sake of brevity.

\subsubsection{Tolerant Control Strategy for Internal Switch Faults}

In the framework of a three-level NPC inverter, in order to exercise the tolerant control of internal (neutral point) switches, it is necessary to connect a serial-connected $\mathrm{H}$-bridge switch in parallel to the neutral-point switches in each arm $\left(\mathrm{Sa2}^{+}, \mathrm{Sa} 1^{-} ; \mathrm{Sb2}{ }^{+}, \mathrm{Sb}^{-}\right.$; and $\left.\mathrm{Sc2}^{+}, \mathrm{Sc}^{-}\right)$as shown in Figure 14. If any of the internal (neutral point) switches $\mathrm{S} a 2^{+}, \mathrm{S} a 1^{-}, \mathrm{S}_{2} 2^{+}, \mathrm{S}_{1} 1^{-}, \mathrm{Sc}^{+}$, and $\mathrm{Sc}^{-}$in the inverter encounter an open-circuit fault, in order for the inverter to remain in operation, it is necessary to make every parallel-connected tolerant control switch operate at once while altering the switching condition of the inverter. For example, if switch $\mathrm{Sc}_{2}{ }^{+}$has an open-circuit fault, where, in this case, the $c$ phase output of the faulty inverter cannot connect to neutral point $o$, the $c$ phase voltage, $v_{c o}$, becomes erroneous and causes current distortion; hence, it is necessary to activate the tolerant control, i.e., disconnecting $\mathrm{H}$-bridge switches in the $c$ phase $\left({\mathrm{S} c 1^{-}}^{-} \mathrm{Sc}_{2}{ }^{+}\right)$, maintaining the tolerant bypass switches $\left(\mathrm{Sc}^{+}, \mathrm{Sc}^{-}\right)$, and allowing the H-bridge switches $\left(\mathrm{S} a 1^{+}, \mathrm{S} a 2^{-}, \mathrm{S}_{1} 1^{+}, \mathrm{S}_{2} 2^{-}, \mathrm{S} c 1^{+}\right.$, and $\left.\mathrm{S} c 2^{-}\right)$to actuate two-level switching of voltage $\mathrm{P}$ and voltage $\mathrm{N}$, that is, changing the three-level inverter output voltage into two-level output where three-phase balanced output is still maintained. Figures 15 and 16 show the fault-tolerant control and the PWM control signal waveforms for the case of inverter internal switch Sc2 ${ }^{+}$with an open-circuit fault, respectively. 


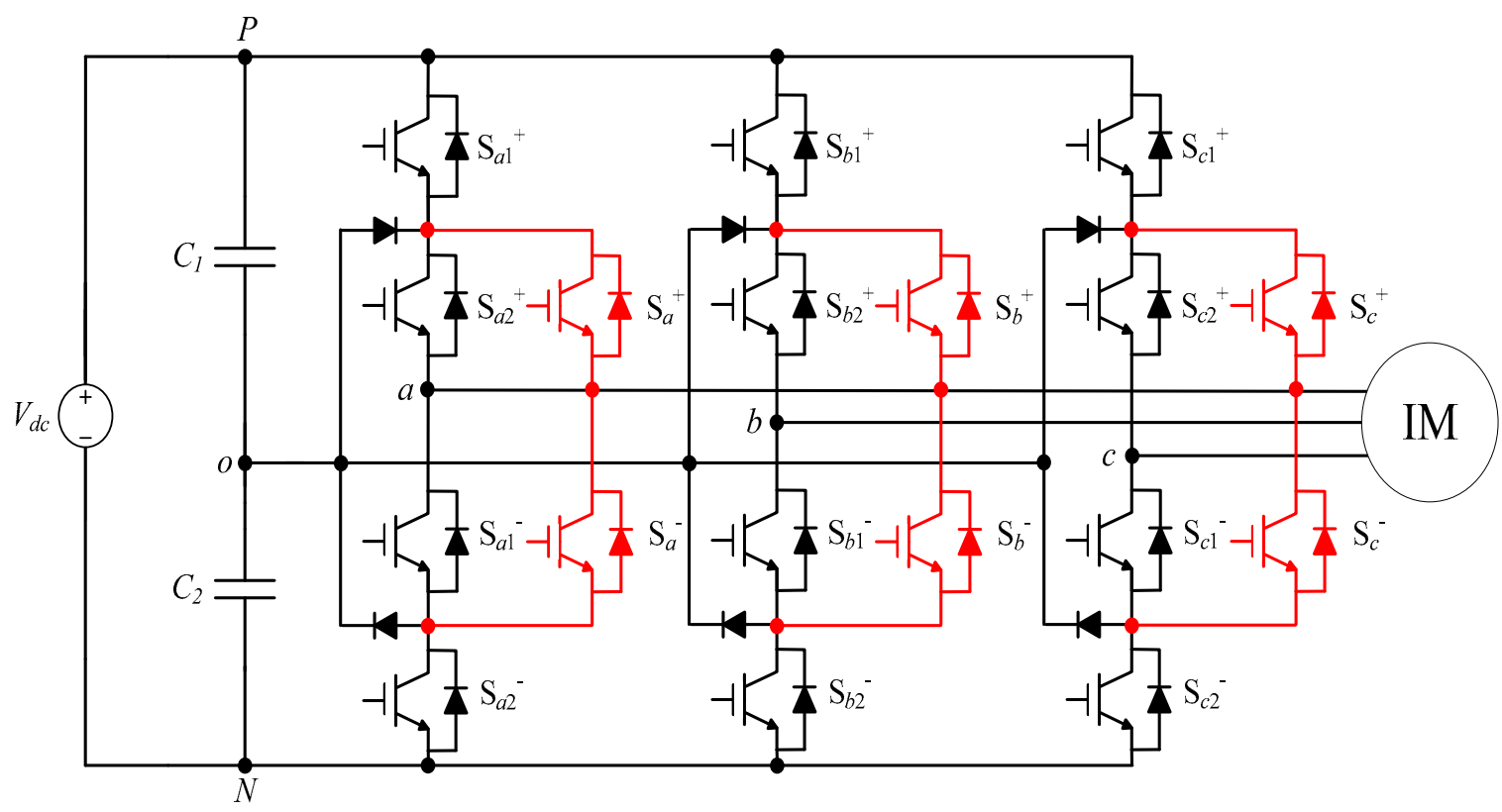

Figure 14. Framework of three-level NPC inverter with additional tolerant control switches.

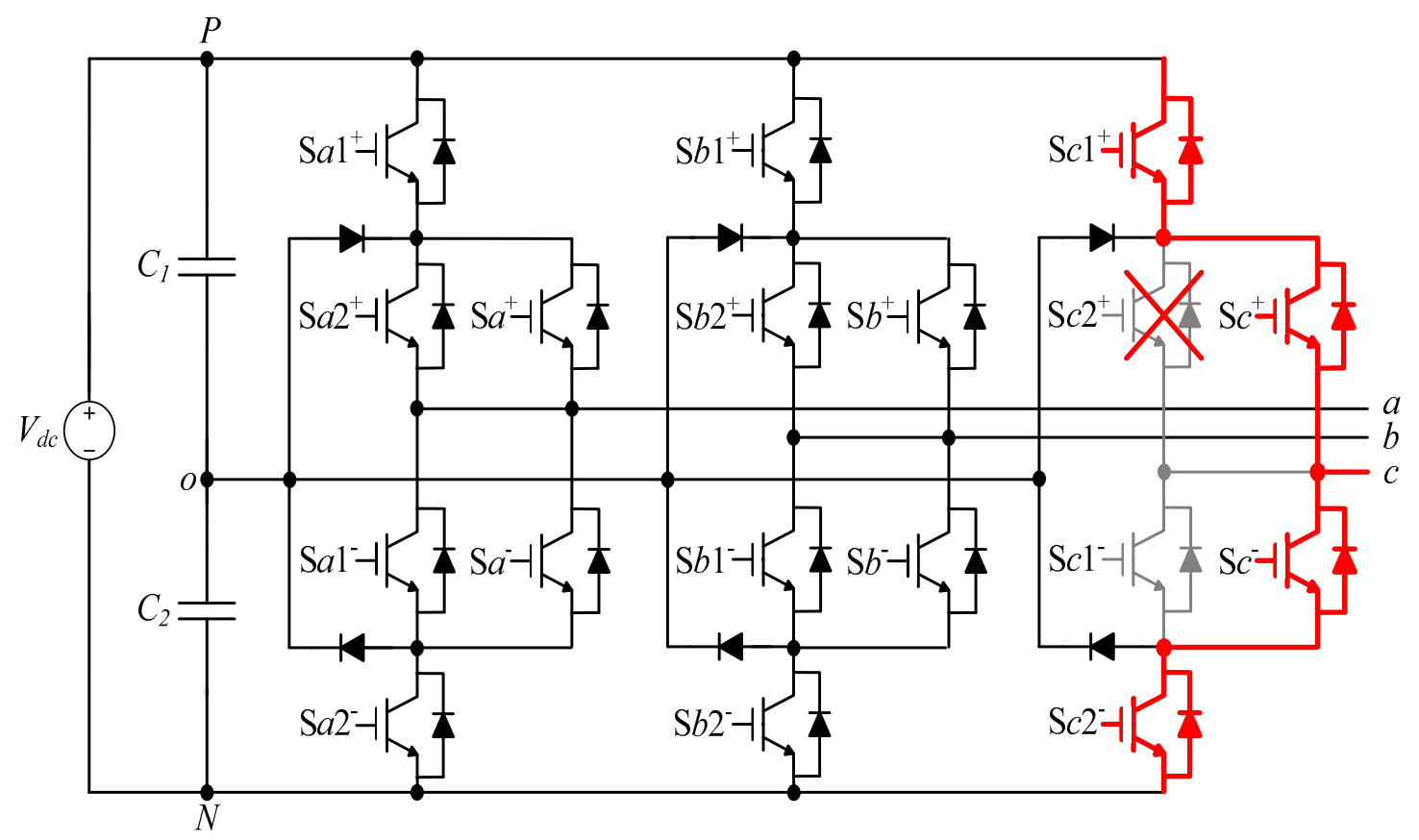

Figure 15. The fault-tolerant control for the occurrence of an open-circuit fault in Sc2+ . 


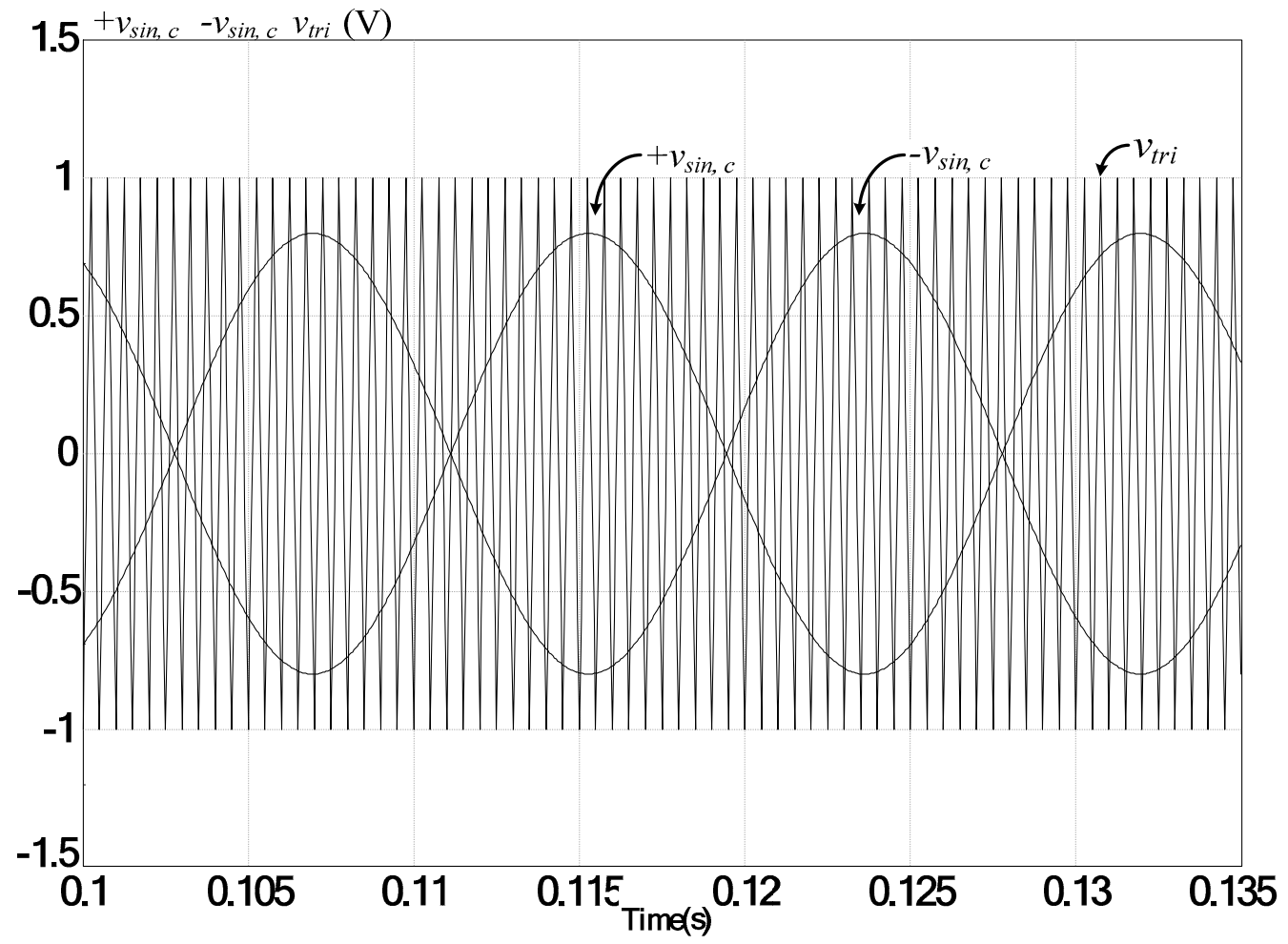

Figure 16. The PWM control signal waveforms for the case of inverter switch $\mathrm{Sc}^{+}$with an open-circuit fault.

\subsection{Tolerant Control Simulations}

When applying tolerant control to an open-circuit fault with external switch $\mathrm{Sa} 1^{+}$, for example, its output line voltage and line current is given as shown in Figure 17. In the case of internal (neutral point) switch $\mathrm{Sc}_{2}{ }^{+}$with an open-circuit fault, its output line voltage and line current are also shown in Figure 18. From Figures 17 and 18, we can observe that if an open-circuit fault occurs at $0.12 \mathrm{~s}$, which would cause the line current of the corresponding phase and three-phase output line voltage to be distorted, particularly so in the affected phase, and the tolerant control strategy is enacted at $0.18 \mathrm{~s}$, then it may observed in the figures that once the tolerant control strategy is enacted that the three-phase output line voltage is downgraded from three-level to two-level output, but it remains a balanced three-phase system despite the fault. Moreover, although the three-phase line current displays a small amount of lag in the beginning of tolerant control due to inductive loads, it maintains a balanced three-phase system output. 


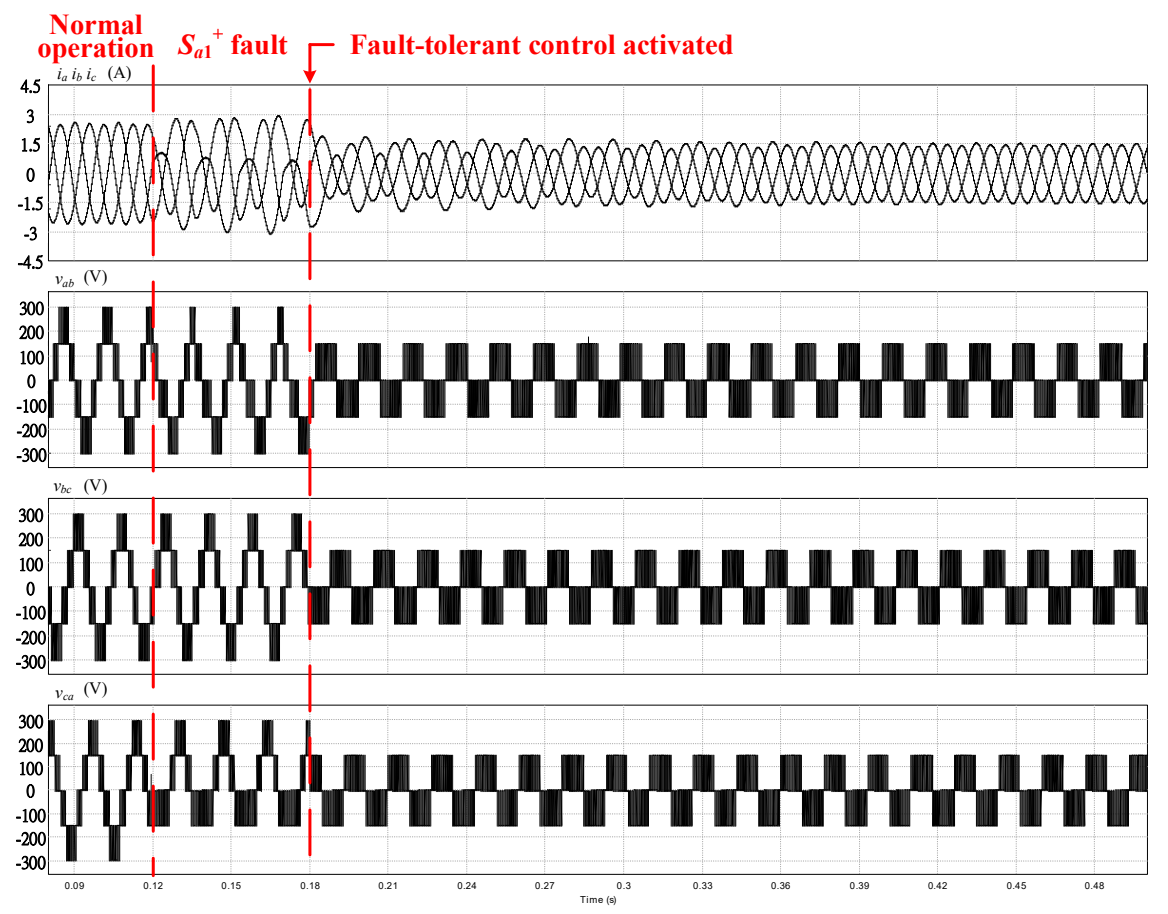

Figure 17. Waveforms of the output line voltage and line current of external switch $S_{a 1}{ }^{+}$with an open-circuit fault and tolerant control.

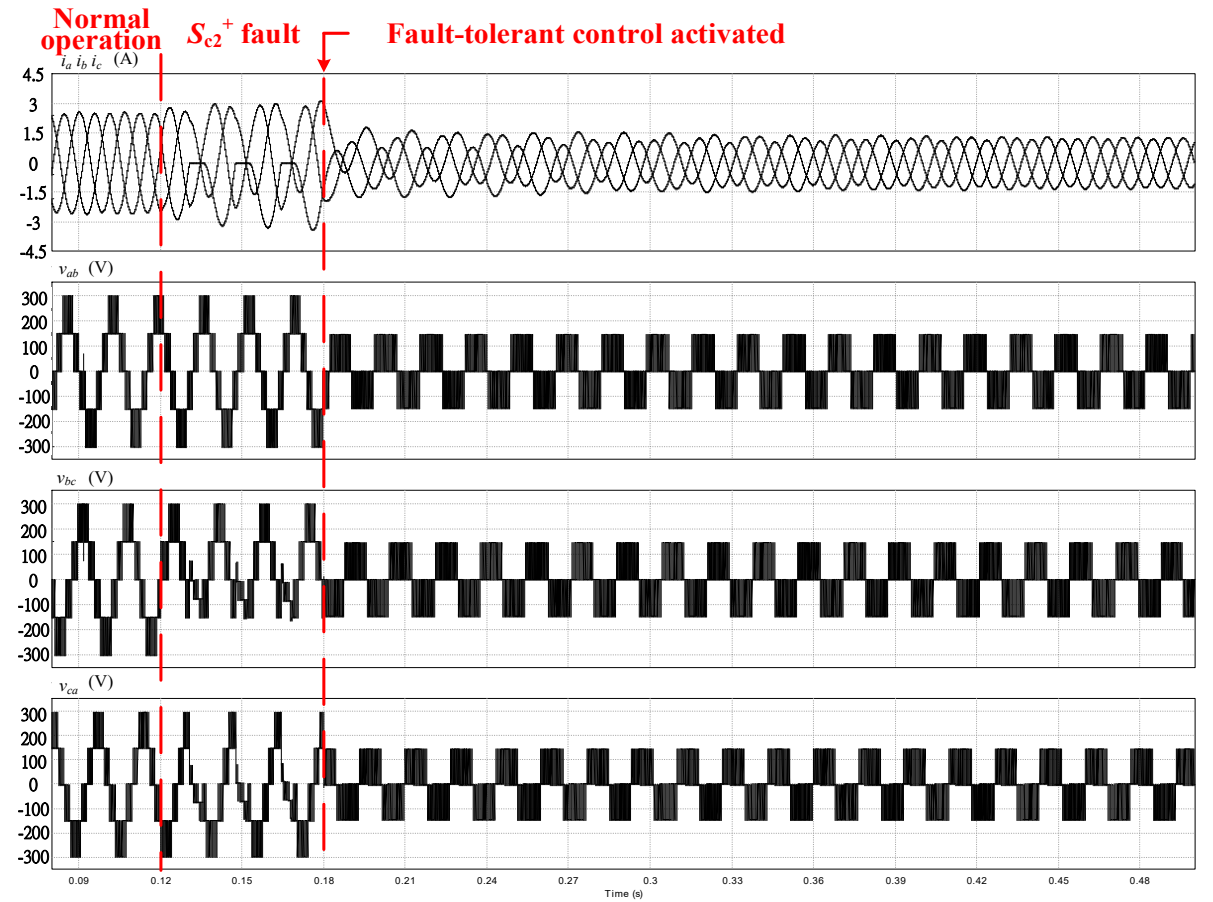

Figure 18. Waveforms of the output line voltage and line current of internal switch $S_{c 2}{ }^{+}$with an open-circuit fault and tolerant control.

According to the analysis of the tolerant control in Section 6.1, other switch failures in different phases will also produce the same results. As such, additional results are not presented here for the sake of brevity. 


\subsection{Tolerant Control Experiments}

Figure 19 shows the three-level neutral-point clamped (NPC) inverter used in this study. To verify the experimental results, this study used the digital signal processor TMS320F28335 as the control core and considered the occurrence of open-circuit faults in the switches to test the fault-tolerant control strategy. Figure 20 shows that the occurrence of an open-circuit fault in the switch $S_{a 1}{ }^{+}$would distort the three-phase output line current and voltage. The fault is particularly severe in the $i_{a}, v_{a b}$, and $v_{c a}$ phases, and the fault-tolerant control strategy can be implemented $0.015 \mathrm{~s}$ after the occurrence of the fault. In this situation, the $a$ phase half-bridge switches $\left(S_{a 1}{ }^{+}\right.$and $\left.S_{a 2}{ }^{-}\right)$are deactivated and the neutral-point switches $\left(S_{a 1}{ }^{-}\right.$and $\left.S_{a 2}{ }^{+}\right)$are activated. The $b$ - and $c$-phase switches still operate normally. The phase angle of the $b$ phase voltage is simultaneously adjusted such that it is $150^{\circ}$ behind the phase angle of the $a$ phase reference voltage, and the phase angle of the $c$ phase reference voltage is adjusted such that it is $150^{\circ}$ ahead of that of the $a$ phase voltage. After the implementation of the fault-tolerant control strategy, the three-phase output line voltage is reduced from five to three levels (Figure 20b); however, after the occurrence of the fault, the output line current and voltage are still maintained via the operation of the balanced three-phase system. Therefore, the motor can still operate normally with a reduced load.

Based on the tolerance control analysis detailed in Section 6.1, the same results can be obtained when other external switches fail.

If any of the internal switches $\mathrm{S} a 2^{+}, \mathrm{S} a 1^{-}, \mathrm{S} b 2^{+}, \mathrm{S} b 1^{-}, \mathrm{S} c 2^{+}$, and $\mathrm{S} c 1^{-}$in the inverter experience an open-circuit fault, in order for the inverter to remain in operation, it is necessary to make every parallel-connected tolerant control switch (as shows in Figure 14) operate at once. If internal (neutral point) switch $\mathrm{Sc}_{2}{ }^{+}$experiences an open-circuit fault, its output line current and voltage are same as shown in Figure 21. The output line current and voltage still maintain the operation of the balanced three-phase system. Hence, the motor can also operate normally with a reduced load.

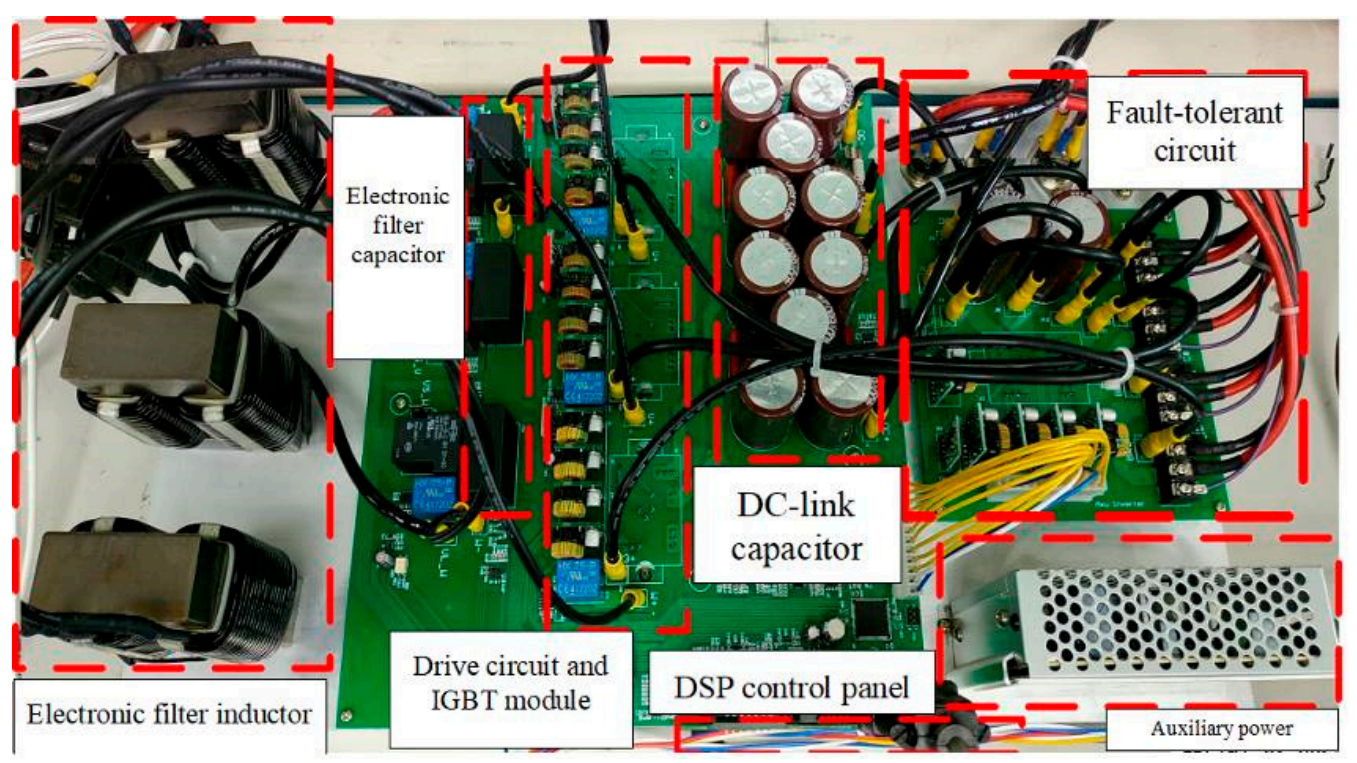

Figure 19. Experimental hardware circuits for the three-level NPC inverter. 


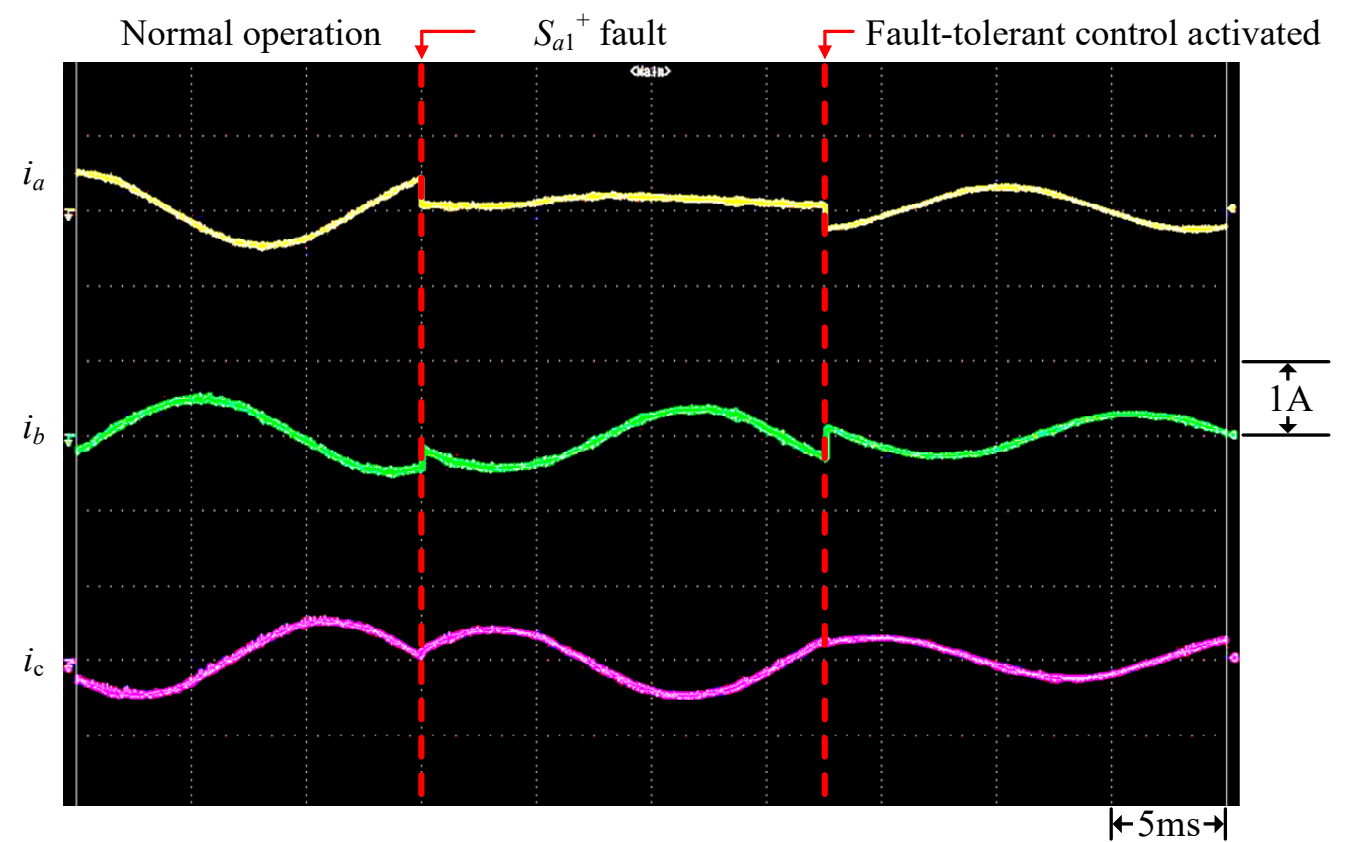

(a)

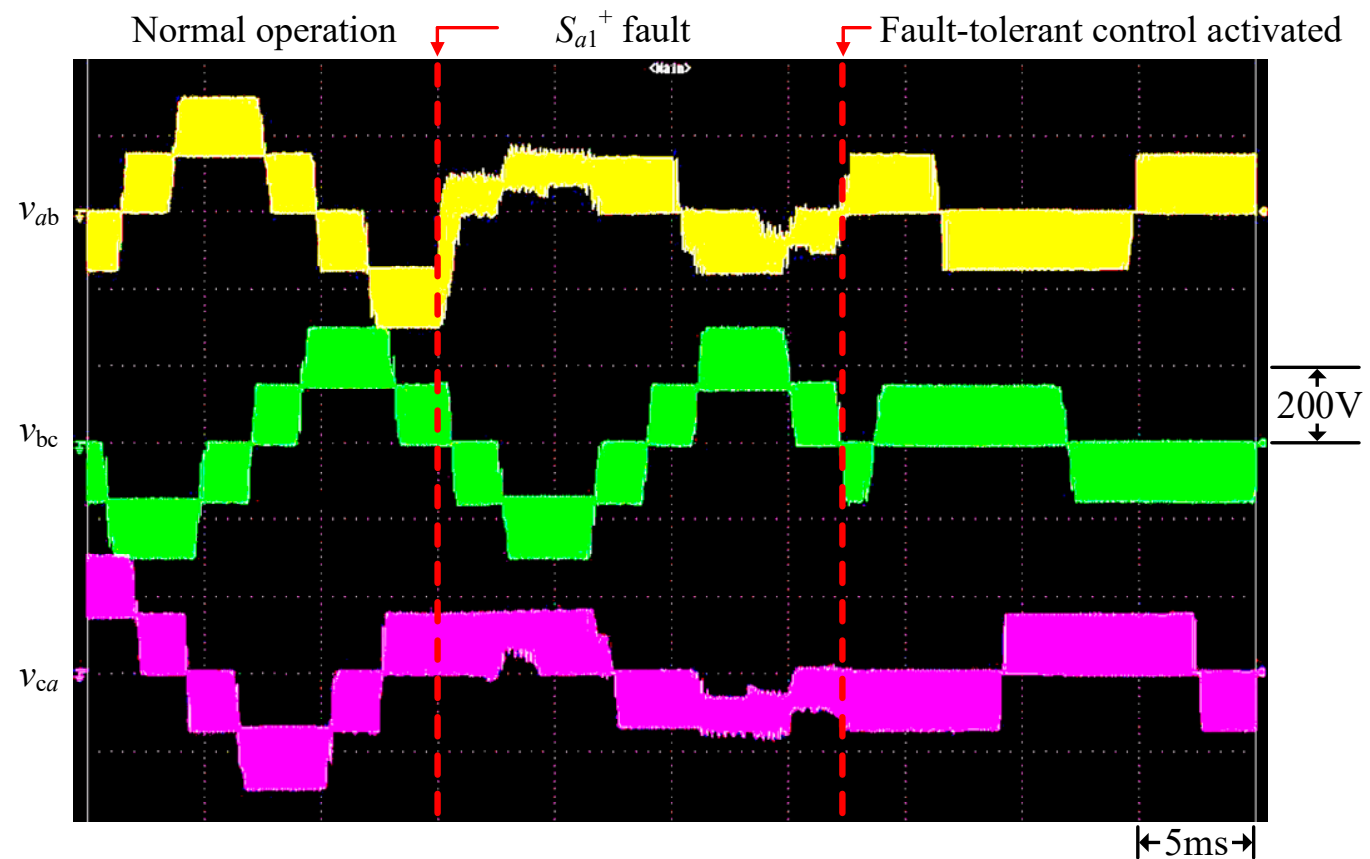

(b)

Figure 20. Measured waveforms of switch $S_{a 1}{ }^{+}$with an open-circuit fault and tolerant control: (a) output line current; (b) output line voltage. 


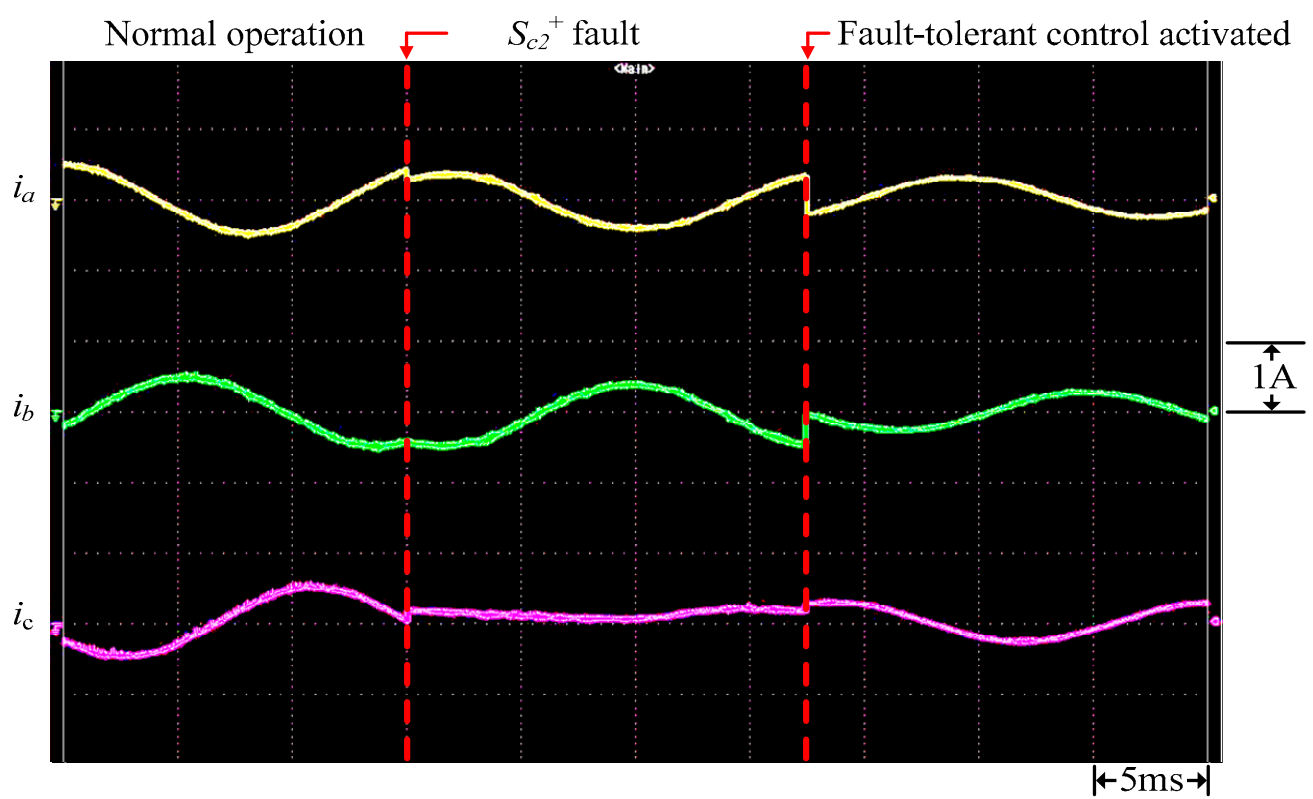

(a)

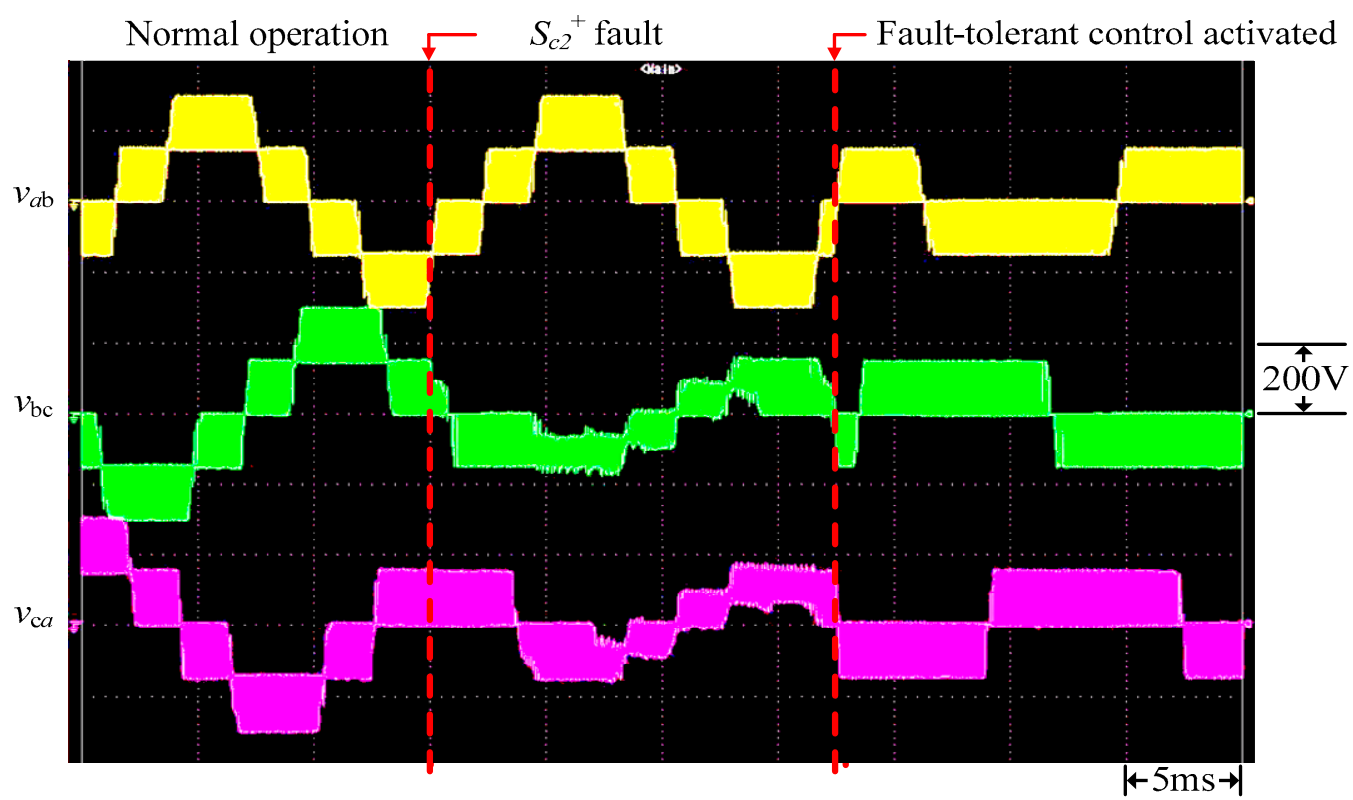

(b)

Figure 21. Measured waveforms of switch $S_{c 2}{ }^{+}$with an open-circuit fault and tolerant control: (a) output line current; (b) output line voltage.

According to the previous analysis in Section 6.1, other internal switch failures will also have the same results.

\section{Conclusions}

This paper has presented a fault diagnosis system for inverters based on extension theory. The system can identify the positions of faulty power transistors in a three-level NPC inverter. The extension theory-based method, as applied here, can be implemented without requiring massive 
data quantities for training, thus being able to reduce the data volume and enable faster identification with higher accuracy. In addition, the tolerant control strategy of the system is able to be implemented as soon as any switch in the inverter becomes faulty, where the inverter is enabled to continue supplying power, enhancing the reliability of power supply by the three-level NPC inverter. Finally, the simulation and experimental results suggest that the system is able to correctly pinpoint the positions of faulty power transistors, and, when any switch becomes faulty, it is able to maintain the output line voltage and line current with three-phase balance by means of the tolerant control strategy, which verifies that the method proposed herein is viable.

Author Contributions: The conceptualization was proposed by K.-H.C., who was also responsible for writing (review and editing) this paper. K.-H.C. completed the formal analysis of the fault diagnosis system and tolerant control algorithm. C.-H.K. carried out the data curation, software programming, simulation, and experimental validation. K.-H.C. was in charge of project administration. All authors have read and agreed to the published version of the manuscript.

Funding: This research was funded by Ministry of Science and Technology, Taiwan, under grant number MOST 109-2221-E-167-016-MY2.

Conflicts of Interest: The authors of the manuscript declare that there are no conflicts of interest with any of the commercial identities mentioned in the manuscript.

\section{References}

1. Rodriguez, J.I.; Leeb, S.B. A multilevel inverter topology for inductively coupled power transfer. IEEE Trans. Power Electron. 2006, 21, 1607-1617. [CrossRef]

2. Escalante, M.F.; Vannier, J.C.; Arzande, A. Flying capacitor multilevel inverters and DTC motor drive applications. IEEE Trans. Ind. Electron. 2002, 49, 809-815. [CrossRef]

3. Tourkhani, F.; Viarouge, P.; Meynard, T.A. Optimal design and experimental results of a multilevel inverter for an UPS application. In Proceedings of the International Conference on Power Electronics and Drive Systems, Singapore, 26-29 May 1997; pp. 340-343.

4. Daher, S.; Schmid, J.; Antunes, F.L.M. Multilevel inverter topologies for stand-alone PV systems. IEEE Trans. Ind. Electron. 2008, 55, 2703-2712. [CrossRef]

5. Naik, R.L.; Udaya, K.R.Y. A novel technique for control of cascaded multilevel inverter for photovoltaic power supplies. In Proceedings of the European Conference on Power Electronics and Applications, Dresden, Germany, 11-14 September 2005; pp. 1-9.

6. Nabae, A.; Takahashi, I.; Akagi, H. A new neutral-point clamped PWM inverter. IEEE Trans. Ind. Appl. 1981, 17, 518-523. [CrossRef]

7. Chen, A.L.; Hu, L.; Chen, L.F.; Deng, Y.; He, X.N. A multilevel converter topology with fault-tolerant ability. IEEE Trans. Power Electron. 2005, 20, 405-415. [CrossRef]

8. Khomfoi, S.; Tolbert, L.M. Fault diagnostic system for a multilevel inverter using a neural network. IEEE Trans. Power Electron. 2007, 22, 1062-1069. [CrossRef]

9. Choi, U.; Lee, K.; Blaabjerg, F. Diagnosis and tolerant strategy of an open-switch fault for T-type three-level inverter systems. IEEE Trans. Ind. Appl. 2014, 50, 495-508. [CrossRef]

10. Altug, S.; Chen, M.Y.; Trussell, H.J. Fuzzy inference systems implemented on neural architectures for motor fault detection and diagnosis. IEEE Trans. Ind. Electron. 2002, 46, 1069-1079. [CrossRef]

11. Peng, Z. An integrated approach to fault diagnosis of machinery using wear debris and vibration analysis. Wear 2003, 255, 1221-1232. [CrossRef]

12. Han, T.; Yang, B.S.; Lee, J.M. A new condition monitoring and fault diagnosis system of induction motors using artificial intelligence algorithms. In Proceedings of the IEEE International Conference on Electric Machines and Drives, San Antonio, TX, USA, 15-18 May 2005; pp. 1967-1974.

13. Pedrayes, F.; Rojas, C.H.; Cabanas, M.F.; Melero, M.G.; Orcajo, G.A.; Cano, J.M. Application of a dynamic model based on a network of magnetically coupled reluctances to rotor fault diagnosis in induction motors. In Proceedings of the IEEE International Symposium on Diagnostics for Electric Machines, Power Electronics and Drives, Cracow, Poland, 6-8 September 2007; pp. 241-246. 
14. Lehtoranta, J.; Koivo, H.N. Fault diagnosis of induction motors with dynamical neural networks. In Proceedings of the IEEE International Conference on Systems, Man and Cybernetics, Waikoloa, HI, USA, 10-12 October 2005; pp. 2979-2984.

15. He, Q.; Du, D.M. Fault diagnosis of induction motor using neural networks. In Proceedings of the International Conference on Machine Learning and Cybernetics, Hong Kong, China, 19-22 August 2007; pp. 1090-1095.

16. Martin-Diaz, I.; Morinigo-Sotelo, D.; Duque-Perez, O.; Romero-Troncoso, R.J. An experimental comparative evaluation of machine learning techniques for motor fault diagnosis under various operating conditions. IEEE Trans. Ind. Appl. 2018, 54, 2215-2224. [CrossRef]

17. Torabi, N.; Sundaram, V.M.; Toliyat, H.A. On-line fault diagnosis of multi-phase drives using self-recurrent wavelet neural networks with adaptive learning rates. In Proceedings of the IEEE Applied Power Electronics Conference and Exposition (APEC), Tampa, FL, USA, 26-30 March 2017; pp. 570-577.

18. Chowdhury, D.; Bhattacharya, M.; Khan, D.; Saha, S.; Dasgupta, A. Wavelet decomposition based fault detection in cascaded $\mathrm{H}$-bridge multilevel inverter using artificial neural network. In Proceedings of the 2nd IEEE International Conference Recent Trends in Electronics, Information \& Communication Technology (RTEICT), Bangalore, India, 19-20 May 2017; pp. 1931-1935.

19. Xu, J.; Song, B.; Zhang, J.; Xu, L. A new approach to fault diagnosis of multilevel inverter. In Proceedings of the Chinese Control and Decision Conference (CCDC), Shenyang, China, 9-11 June 2018; pp. 1054-1058.

20. Li, W.; Li, G.Y.; Zeng, R.; Ni, K.; Hu, Y.H.; Wen, H.Q. The fault detection, localization, and tolerant operation of modular multilevel converters with an insulated gate bipolar transistor (IGBT) open circuit fault. Energies 2018, 11, 837. [CrossRef]

21. Liu, Y.Q.; Li, D.H.; Jin, Y.; Wang, Q.B.; Song, W.L. Research on unbalance fault-tolerant control strategy of modular multilevel photovoltaic grid-connected inverter. Energies 2018, 11, 1368. [CrossRef]

22. Jung, J.H.; Ku, H.K.; Son, Y.D.; Kim, J.M. Open-switch fault diagnosis algorithm and tolerant control method of the three-phase three-level NPC active rectifier. Energies 2019, 12, 2495. [CrossRef]

23. Ahmadipour, M.; Hizam, H.; Othman, M.L.; Radzi, M.A.M.; Chireh, N. A fast fault identification in a grid-connected photovoltaic system using wavelet multi-resolution singular spectrum entropy and support vector machine. Energies 2019, 12, 2508. [CrossRef]

24. He, Z.; Zhang, X.C.; Liu, C.; Han, T. Fault prognostics for photovoltaic inverter based on fast clustering algorithm and Gaussian mixture model. Energies 2020, 13, 4901. [CrossRef]

25. Kwon, B.H.; Kim, S.H.; Kim, S.M.; Lee, K.B. Fault diagnosis of open-switch failure in a grid-connected three-level Si/SiC hybrid ANPC inverter. Electronics 2020, 9, 399. [CrossRef]

26. Li, M.; Li, G. Based on theory of extenics research assessment and classification of soil erosion. In Proceedings of the World Automation Congress, Puerto Vallarta, Mexico, Mexico, 24-28 June 2012; pp. 1-6.

27. Chen, P.Y.; Chao, K.H.; Wu, Z.Y. An optimal collocation strategy for the key components of compact photovoltaic power generation systems. Energies 2018, 11, 2523. [CrossRef]

28. Wang, M.H.; Huang, M.L.; Jiang, W.J. Maximum power point tracking and harmonic reducing control method for generator-based exercise equipment. Energies 2016, 9, 103. [CrossRef]

29. Ju, Y.; Yu, Y.; Ju, G.; Cai, W. Extension set and restricting qualifications of matter-elements' extension. In Proceedings of the 3rd International Conference on Information Technology and Applications, Sydney, NSW, Australia, 4-7 July 2005; pp. 395-398.

30. Xiao, L.; Li, X. Supplier selection based on matter element analysis. In Proceedings of the fourth International Conference on Transportation Engineering, Chengdu, China, 19-20 October 2013; pp. 551-557.

Publisher's Note: MDPI stays neutral with regard to jurisdictional claims in published maps and institutional affiliations.

(C) 2020 by the authors. Licensee MDPI, Basel, Switzerland. This article is an open access article distributed under the terms and conditions of the Creative Commons Attribution (CC BY) license (http://creativecommons.org/licenses/by/4.0/). 